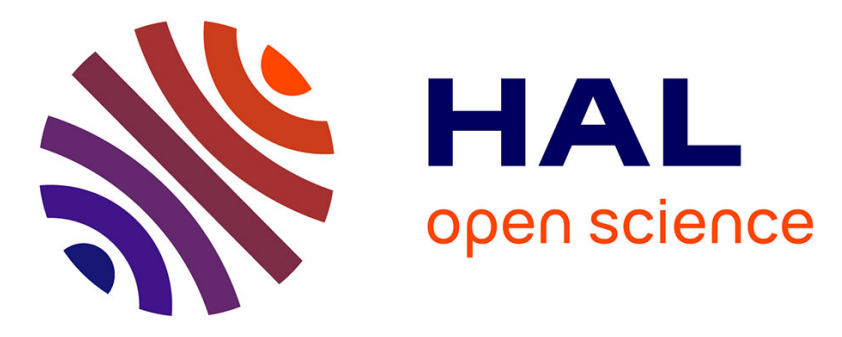

\title{
RNA ribose methylation (2'-O-methylation): Occurrence, biosynthesis and biological functions
}

Lilia Ayadi, Adeline Galvanin, Florian Pichot, Virginie Marchand, Yuri Motorin

\section{- To cite this version:}

Lilia Ayadi, Adeline Galvanin, Florian Pichot, Virginie Marchand, Yuri Motorin. RNA ribose methylation (2'-O-methylation): Occurrence, biosynthesis and biological functions. Biochimica et Biophysica Acta - Gene Regulatory Mechanisms , 2018, 1862 (3), pp.253-269. 10.1016/j.bbagrm.2018.11.009 . hal-01969343

\section{HAL Id: hal-01969343 \\ https://hal.univ-lorraine.fr/hal-01969343}

Submitted on 22 Oct 2021

HAL is a multi-disciplinary open access archive for the deposit and dissemination of scientific research documents, whether they are published or not. The documents may come from teaching and research institutions in France or abroad, or from public or private research centers.
L'archive ouverte pluridisciplinaire HAL, est destinée au dépôt et à la diffusion de documents scientifiques de niveau recherche, publiés ou non, émanant des établissements d'enseignement et de recherche français ou étrangers, des laboratoires publics ou privés.

\section{(ㄷ)(1) $\$$}

Distributed under a Creative Commons Attribution - NonCommerciall 4.0 International 
Version of Record: https://www.sciencedirect.com/science/article/pii/S1874939918300804

Manuscript_9df77459c544c4a688a23d39f06a3b0d

Prepared for BBA special issue Gene Regulatory Mechanisms (revised version)

RNA ribose methylation (2'-O-methylation): occurrence, biosynthesis and biological functions

Lilia AYADI ${ }^{1}$, Adeline GALVANIN ${ }^{1}$, Florian PICHOT ${ }^{2}$, Virginie MARCHAND ${ }^{2}$, Yuri MOTORIN ${ }^{1 *}$

${ }^{1}$ UMR7365 IMoPA CNRS-Lorraine University, Biopôle, 9 avenue de la forêt de haye, 54505 Vandoeuvre-lesNancy, France

${ }^{2}$ UMS2008 IBSLor CNRS-INSERM-Lorraine University, Biopôle, 9 avenue de la forêt de haye, 54505

Vandoeuvre-les-Nancy, France

*Corresponding author

Yuri MOTORIN

UMR7365 IMoPA CNRS-Lorraine University

BioPôle

9 avenue de la forêt de haye

54505 Vandoeuvre-les-Nancy

France

Tel +33-3-72746629

e-mail : Yuri.Motorin@univ-lorraine.fr

Keywords: RNA modification, epitranscriptome, tRNA, rRNA, mRNA, sn/snoRNA, ribose methylation 


\section{Abstract}

Methylation of riboses at 2'-OH group is one of the most common RNA modifications found in number of cellular RNAs from almost any species which belong to all three life domains. This modification was extensively studied for decades in rRNAs and tRNAs, but recent data revealed the presence of 2'-O-methyl groups also in low abundant RNAs, like mRNAs.

Ribose methylation is formed in RNA by two alternative enzymatic mechanisms: either by stand-alone protein enzymes or by complex assembly of proteins associated with snoRNA guides (sno(s)RNPs). In that case one catalytic subunit acts at various RNA sites, the specificity is provided by base pairing of the sno(s)RNA guide with the target RNA. In this review we compile available information on 2'-OH ribose methylation in different RNAs, enzymatic machineries involved in their biosynthesis and dynamics, as well as on the physiological functions of these modified residues. 


\section{Introduction and historical overview of early studies on RNA 2'-0-methylation}

Ribose 2'-O-methylation is one of the most common and widespread type of RNA modification commonly found in in ribosomal RNA (rRNA), transfer RNA (tRNA), small nucleolar RNA (snRNA) and, as reported recently, in messenger RNA (mRNA). This modification consists of the methylation of the ribose 2'-OH moiety (enzymatic transfer of methyl $\mathrm{CH}_{3}$-group from methyl donor to RNA substrate) and can therefore occur in all 4 nucleotides and other non-canonical nucleotides (Figure 1a). Despite their discovery already in the 60's, RNA 2'-O-methylations remained for a long time enigmatic, without any attributed cellular function. Only recently, complete distribution profiles of these residues have been reported, especially for low abundant RNAs and some physiological functions become clear. In this review, we provide a summary of the current knowledge on the presence and precise locations of 2'-O-methylations in different bacterial, archaeal and eukaryal RNAs. Enzymatic mechanisms involved in their biosynthesis and biological functions of 2'-O-methylation, as improvement of RNA stability and fine modulation of its conformation, as well as its importance in ribosomal translation and innate immunity are discussed. Methods for detection of those modified nucleotides are briefly discussed here since covered by other recent reviews [1-4].

Biological RNA methylation was extensively studied already in 60-70's (Figure 1b) and established the presence of methyl groups in tRNAs and rRNAs [5], but not in bacterial mRNAs [6]. Major efforts were concentrated on mapping of those modified residues in highly abundant RNAs, like rRNAs $[7,8]$ from different model organisms, as well as some isolated tRNAs [9]. This provided the first ideas on the distribution and the exact locations of 2'-O-methylations [10,11], even if only a subset of sites has been precisely mapped at that time, due to technological limitations.

In parallel, biochemical approaches to study RNA modification were established $[8,12,13]$ using undermethylated RNA from methionine-starved cells for in vitro tests for RNA modification [14]. The major impediment for detailed biochemical characterization was the lack of appropriate unmodified RNA substrates. Biochemical characterization with "undermodified" or inappropriately modified heterologous RNAs as substrates was thus extensively used $[15,16]$.

Mid and late 70's brought even more advances in the field, by measuring of exact stoichiometry of modified nucleotides (including 2'-O-methylations) in eukaryotic rRNAs [17,18]. 2'-0-methylation profile of tRNAs from both selected bacterial species and eukaryotes was more precisely established [19-21]. These studies also confirmed earlier observations [22] on the existence of hypo(or hyper) methylated isoforms of tRNAs [23]. In addition to stable and abundant RNAs, 2'-O-methylations were found in U2 snRNA [24] and in various preparations of eukaryotic mRNAs [25-28].

Functions of these modified residues in various RNAs still remained largely unknown, but some influence on RNA conformation was already noticed [29,30], and pioneering studies on antibiotic resistance demonstrated importance of ribose methylation for thiostrepton resistance in Streptomyces azureus [31,32].

\section{Mapping of 2'-0-methylated residues by next-generation sequencing}

\section{RiboMethSeq, 2'OMe-seq, $\mathrm{Nm}$-Seq}

In 2015, the group of H. Nielsen published a high-throughput approach for mapping of ribose methylation on an Ion Torrent sequencing platform [33]. One year later, we adapted the protocol to an Illumina 
sequencing platform and reduced significantly the required RNA amounts (1,000x less), thereby allowing first analyses of clinical samples [34-36]. Both protocols are based on a reduced cleavage of the RNA phosphodiester bond that is $3^{\prime}$ adjacent to a 2'-O-methylation in RNA. A fragmentation of RNA in alkaline conditions produces a collection of RNA fragments starting or ending at all RNA positions except at position +1 ( $5^{\prime}$-end) or at the 2'-O-methylated residue ( $3^{\prime}$-end). Therefore, after fragments end-repair, library preparation and sequencing, $5^{\prime}$ - and $3^{\prime}$ - end coverage is calculated and transformed into scores defining the level of methylation at a single nucleotide resolution. Another method called 2'OMe-seq based on RT-arrest at 2'-O-methylated residues at low dNTP concentration was developed allowing mapping of previously unknown positions in mouse rRNA [37]. Finally, 2 other groups independently developed a new strategy to map Nm in low abundant RNAs. These methods (RibOxi-Seq and Nm-Seq) rely on the differential reactivity of 2'-O-methylated and 2'-hydroxylated nucleosides to periodate oxidative cleavage, and on a selective enrichment of $2^{\prime}$-O-methylated sites [38,39].

\section{Presence of 2'-0-methylated residues in cellular RNAs}

\section{tRNA 2'-O-methylation}

Transfer RNA (tRNA) molecules contain multiple 2'-O-methylated residues [40], but the number of 2'-Omethylated sites has evolved from a simple to a more complex pattern from bacteria to human.

\section{Bacterial tRNA 2'-0-methylation}

Three different 2'-O-methylated positions have been discovered in tRNA from the model organism E. coli (Figure 2, Supplementary Table 1) [40]. The major site is located in the D-loop at position 18, where the highly conserved $\mathrm{G}$ residue is converted to a 2'-O-methylated guanine $(\mathrm{Gm})$ in many tRNA species. The two other 2'-O-methylated residues located in the anticodon loop at positions 32 and 34 (tRNA wobble position) correspond to $\mathrm{Cm}$ and $\mathrm{Um} / \mathrm{cmnm}^{5} \mathrm{Um}$ residues and are present in a subset of tRNAs.

All studied bacterial species seem to contain a 2'-O-methylation at Cm34 or Um34, whereas Gm18 is present only in Gram-negative bacteria, with the exception of the Gram-positive Geobacillus sp. [41]. Modified $\mathrm{Cm} 32$ is present in all Gram-negative species, and is also probably conserved in Gram-positive bacteria, but data are sparse [20]. Except for E. coli and more generally Gram-negative species, bacterial 2'O-methylation in tRNA is rather poorly characterized and data for the majority of pathogenic bacteria are still lacking.

\section{Archaeal tRNA 2'-0-methylation}

In archaea, although tRNA 2'-O-methylation is poorly studied, four positions were found to be modified: the universally conserved positions 32 and 34 , as well as two additional positions 39 and 56 . The latter is unique to archaea [42]. Compared to eubacteria, archaea lack Gm18 [43,44].

\section{Eukaryotic tRNA 2'-O-methylation}

In yeast S. cerevisiae, in addition to the conserved $\mathrm{Gm} 18, \mathrm{Cm} 32$ and $\mathrm{Nm} 34$ residues [45], 2 other positions are 2'-O-methylated: Nm4 and Um44. Um44 is frequent in cytoplasmic tRNA containing a long variable loop such as tRNA ${ }^{\text {Ser }}$ [46]. Concerning Nm4, this modification is the only one known to be in the middle of a duplex region in tRNA [47]. Methylations $\mathrm{Cm} 32$ and Nm34 in the anticodon loop are prerequisite for $\mathrm{m}^{1} \mathrm{G}$ 
synthesis at position 37 , which is an intermediate step in the biosynthesis of yW37 (wybutosine) $[48,49]$.

In vertebrates, the 5 positions described above for other species are similar with additional complexity: $\mathrm{Cm} / \mathrm{Um} 4 ; \mathrm{Gm} 18 ; \mathrm{Cm} / \mathrm{Um} / \Psi_{\mathrm{m} 32} ; \mathrm{Cm} / \mathrm{Gm} 34$ and $\mathrm{Um} 44$. Moreover, two other sites are characterized for vertebrate tRNA 2'-O-methylation. The first one is $\operatorname{Tm}\left(\mathrm{m}^{5} \mathrm{Um}\right) 54$ in the $\mathrm{T} \Psi$-loop that sometimes replaces the universally conserved T54 modified residue [50]. The second one is $\Psi \mathrm{m} 39$ [40,51]. In higher eukaryotes, 2'O-methylations are often part of a more complex modified residue, where base modification is coupled with ribose methylation (like $\mathrm{f}^{5} \mathrm{Cm}$ [52], $n \mathrm{~cm}^{5} \mathrm{Um}$ [53] and $\mathrm{m}^{1} \mathrm{Am}$ [54]).

\section{rRNA 2'-O-methylation}

2'-O-ribose methylation is one of the major modifications (with pseudouridine) found in rRNA $[55,56]$ and this through all three life domains. The number of 2'-O-methylations in rRNA increases in the most complex organisms being up to ten-fold higher in human in comparison to bacteria, however, despite the differences in the machinery involved in their biosynthesis, many positions are evolutionarily conserved between bacteria and archaea/eukaryotes. Most of the time 2'-0-methylations occur in functionally important domains of the two ribosomal subunits, essentially in proximity of the Peptidyl Transferase Center (PTC) and of the Decoding Center (DC) $[57,58]$.

\section{Bacterial rRNA 2'-O-methylation}

In contrast to eukaryotes, where rRNA 2'-O-methylations are quite numerous, such residues are relatively rare in bacterial rRNAs.

Ribose methylation was essentially found at four highly conserved nucleotides: C1402 of the SSU-16S rRNA and G2251, C2498 and U2552 of the LSU-23S rRNA (for review [59]). Almost all bacteria have a modified $16 \mathrm{~S}-\mathrm{Cm} 1402$, which participates in P-site formation and seems to improve the precision of initiation codon selection [58]. In addition, crystal structure of the E. coli 30 S subunit complex revealed that $\mathrm{Cm} 1402$ is stabilized in a C3'-endo conformation to promote its interaction with the mRNA.

All three 23S rRNA 2'-O-methylated residues Gm2251, Cm2498, Um2552 are located in the PTC. While Gm2251 and Cm2498 appear to be dispensable for cell viability [60], Um2552 is essential and is 2'-Omethylated in the majority of living organisms from bacteria to human, suggesting its important function.

- Gm2251 stays in close contact with the CCA-end of the P-site bound tRNA [61]. Bacteria lacking this modification do not show any phenotype under normal growth conditions [62]. However in yeast, the same modification present in mitochondrial rRNA (Supplementary Table 2) is required for cell viability [63].

- Um2552 is one of the conserved nucleotides in the ribosomal A site and interacts with aminoacyl-tRNA. Binding of the CCA-end of tRNA to the A-site of the ribosome involves a Watson-Crick base pairing between G2553 of the 235 rRNA and C75 of tRNA [64] and methylation of the neighboring U2552 may influence the binding of aminoacyl tRNA to the A-site [65]. Since A- and P-loops of the $23 S$ rRNA contain Gm2251 and Um2552, respectively, one can propose that they may perform similar functions regarding the binding of tRNA to A- and P-sites [59]. Although the 2'-O-methylation of U2552 is not necessary for the function of in vitro reconstituted ribosomes, the substitution of uridine nucleotide or deletion of the corresponding methyltransferase affect growth and ribosome assembly [66-68].

In general, 2'-O-methylated residues found in E. coli rRNA are conserved, since in Thermus thermophilus, a relatively distant bacterium, a single ribose-methylated residue, $\mathrm{m}^{4} \mathrm{Cm} 1402$ was observed in $16 \mathrm{~S}$ rRNA [69], 
while Mycobacteria smegmatis SN2 rRNAs seem to contain one additional site of 2'-0-methylation [70].

\section{Archaeal rRNA 2'-O-methylations}

A map of predicted archaeal rRNA 2'-O-methylations has been established on the basis of high-throughput analysis of highly expressed sRNAs from 7 different archaeal species [71]. It shows that 2'-O-methylations are clearly clustered in functional areas of rRNA, suggesting their contribution to the folding, structural stabilization, assembly and function of the ribosome. However, most of predicted 2'-O-methylation positions were not validated experimentally. Interestingly, hyperthermophilic archaea N. equitans and $I$. hospitalis contain additional 2'-O-methylation residues within 150 3'-end nucleotides of 16S rRNA [72].

\section{Yeast S. cerevisiae rRNA 2'-0-methylations}

To date a total of 55 2'-O-methylated sites have been found in yeast rRNA [33,34,73,74]: 18 in the SSU-18S rRNA ( $8 \mathrm{Am}, 3 \mathrm{Cm}, 6 \mathrm{Gm}$ and $1 \mathrm{Um}$ ), and 37 in the LSU-25S (12 Am, $7 \mathrm{Cm}, 10 \mathrm{Gm}$ and $8 \mathrm{Um}$ ). No 2'-Omethylation sites have been described for $5.8 \mathrm{~S}$ and $5 \mathrm{~S}$ rRNAs. Orthogonal methods have been used to validate and/or quantify some of the modified sites by deletion of genes encoding the corresponding C/Dbox snoRNA guides $[33,34]$ or by nucleoside analysis [75]. A clear mapping of 2'-O-methylated riboses on both 2D and 3D structures of both yeast $18 \mathrm{~S}$ and 25S rRNA is now available and showed that the majority of modified residues are located close to the functional area of the ribosome: the DC (equivalent of A-site of 40S) and the PTC ( $A$ and P site of 60S), as well as in the inter-subunit region of the ribosome [76]. Position 2347 of $25 \mathrm{~S}$ rRNA is 2 '-O-methylated either on a $U$ or a partially pseudouridylated residue $[75,77]$.

Concerning yeast mitochondrial rRNA 2'-O-ribose methylation, two positions Gm2270 and Um2791, which are conserved in other species have been detected in the LSU-21S rRNA by primer extension experiments [78].

\section{Higher eukaryotic rRNA 2'-0-methylation in human and mouse models}

Recently, high-throughput and MS approaches have been applied to different cell lines to map and quantify 2'-O-methylations in human rRNAs [37,38,79-82]. In this review, we have compiled all these data to give an updated view of 2'-O-methylations sites in human rRNAs (Supplementary Table 2)

(i) As many as 46 potentially 2'-O-methylated positions were reported in human SSU-18S rRNA by different studies. Majority of them (41 sites) were recently confirmed by different high-throughput sequencing methods, by MS and/or by fibrillarin knockdown (Figure 3a and Supplementary Table 2) [37,38,79-83]. Methylation was not confirmed for nucleotides G1536, U1602 and U1668 [38,79] initially reported by Maden [83]. U1668 was probably incorrectly mapped and the corresponding GCC-U/ $\psi \mathrm{m}-\mathrm{GC}$ sequence should be assigned to position 18S-1232 [79], but validation is missing for this position. MS-mapping also reported Cm621 [82], but this position was newer found in other studies.

(ii) Precise comparison of human LSU-28S rRNA modifications is complicated due to various reference sequences used in independent studies. Early studies used 28S rRNA entry GeneBank U13369 as a reference sequence, but recent high-throughput approaches were referenced to NR_046235, which has multiple insertions of nucleotides. Thus, both "new" and "old" numbering schemes are used in parallel in different studies.

Mapping of 2'-O-methylations in human 28S rRNA by Maden in 80's reported over 50 modification sites, 
however, the exact location of several nucleotides remained unclear [84]. Later, additional positions have been mapped by RT primer extension at low dNTP concentration [85]. Application of recent highthroughput mapping technologies mostly confirmed previous results and allowed to extend this list to 67 modification sites [37,80,82,84,85] (Figure 3b, Supplementary Table 2). The signal for Am1323 was detected in $2^{\prime}$ OMet-Seq and RibOxi-Seq experiments $[37,38]$ and its partial methylation was confirmed by MS analysis [82], however no RiboMeth-Seq signal was found at this position $[79,80]$.

Three previously reported sites were not retained in the final list:

- Um1760/1773 (old/new numbering), found to be modified at $70 \%$ by MS analysis [82], but never seen by other approaches.

- Cm2279/2292 (old/new numbering), reported by 2'OMet-Seq [37] and predicted to be methylated by SNORD48 [86]. This position was not confirmed by other approaches, RibOxi-Seq, RiboMeth-Seq and MS $[38,79,80,82]$.

- Gm2435/2448 (old/new numbering), captured in interaction with SNORD2 in 4 different CLIP experiments in HEK293 cells [87], but having only low RiboMeth-Seq scores, indicating partial methylation, if any. Not confirmed by global MS analysis [82].

(iii) Two 2'-O-methylated sites (Um14 and Gm75) are present in human 5.8S rRNA. The first evidence for their presence was given already in 1975 [88]. In the nucleolus of HeLa cells Um75 is fully methylated, whereas the partially methylated Um14 is further modified in the cytoplasm after incorporation of the $5.8 \mathrm{~S}$ rRNA into mature ribosomes [89].

In conclusion, human rRNAs totalize altogether 110 2'-O-methylated sites (41 sites in SSU-18S rRNA, 67 sites in LSU-28S and 2 in 5.8S rRNA) (Supplementary Table 2).

Until now, very little information was available on mouse rRNA 2'-O-methylation. This was investigated only recently [37] using rRNAs from E14 mouse embryonic stem cells (ESCs) and globally both 2'-O-methylated positions and their methylation status are quite well conserved between human and mouse. This also correlates with a strong conservation of snoRNAs between the two species. The only exception found yet is Gm4166/4196 which was not found in mouse and SNORD31 which is required as guide for this methylation in human cells has no equivalent in mouse.

\section{rRNA modification in vertebrate mitochondria}

To date, only three positions were found to be 2'-0-methylated in hamster [90] and human [91,92] mitochondrial rRNA. These positions (Gm1145, Um1369 and Gm1370) are localized in the peptidyl transferase center of LSU-16S mitochondrial rRNA. Whereas the two first are conserved in other species, the third one was only found in vertebrate LSU-16S mitochondrial rRNA (Supplementary Table 2).

\section{rRNA 2'-0-methylation in other eukaryotic organisms}

In addition to vertebrates, several studies performed analysis of 2'-O-methylation sites in other lower and higher eukaryotes, the most studied are frog Xenopus laevis, plant Arabidopsis thaliana, protist Euglena gracilis and worm Caenorhabditis elegans. Only partial rRNA modification maps have been established for those species, but a general conservation of 2'-O-methylation sites with human and yeast was noticed $[83,84,93-95]$. 


\section{snRNA/snoRNA 2'-O-methylation}

Spliceosomal snRNAs harbor numerous 2'-O-methylated residues (Figure 4). All snRNAs (except U6 and U6atac) possess a trimethylguanosine $\left(\mathrm{m}^{2,2,7} \mathrm{G}\right)$ cap structure followed by two $2^{\prime}$-O-methylated residues that are introduced by the enzymes CMTr1 and CMTr2 during cap formation [96,97]. In addition, snRNAs contain internal 2'-O-methylated residues clustered in functionally important regions that participate in base-pairing with pre-mRNAs or with other snRNAs [24,98]. In mammalian cells, internal snRNA modifications appear to be catalyzed by small Cajal body specific RNAs (scaRNAs) (for review, [99]). Recently, using the RiboMethSeq approach, it was proposed that most of ribose methylations of snRNAs are almost fully modified and required for splicing activity [100]. However, the methylation pattern may vary depending on the conditions used and may contribute to splicing modulation [101].

So far, 2'-O-methylated residues have not been described as part of minor snRNAs, scaRNAs or snoRNAs, but it will of interest to investigate these RNA species by high-throughput technologies.

\section{2'-O-methylations in SiRNA/piRNA/miRNA}

In eukaryotes, small non-coding RNAs are central components of the RNA silencing pathway and play important roles in many biological processes. Their levels are tightly controlled in vivo through the balance of their biogenesis and turnover. Indeed, perturbations in their abundance are associated with many developmental and physiological defects. One of the major mechanisms controlling this balance is the 2'-Omethylation on the $2^{\prime}-\mathrm{OH}$ of the $3^{\prime}$-terminal ribose in small RNAs (for review, [102,103]).

\section{2'-O-methylations in mRNAs}

Ribose 2'-0-methylation in eukaryotic mRNAs was known from the 70's [25-27], precisely on the first and sometimes second cap-proximal nucleotides ( $\mathrm{N} 1$ and N2, where $\mathrm{N}$ corresponds to any nucleotide), resulting in Cap1- (m7GpppNmN) or Cap2- (m7GpppNmNm) mRNA. N1 (and N2) methylation was shown to serve as a molecular signature of "self" to escape detection by the immune innate system (see below).

More recently, with the development of high-throughput Nm-seq technology (based on periodate oxidative cleavage), it was proposed that internal ribose 2'-O-methylation is also present in mRNAs [39]. Thousands of $\mathrm{Nm}$ sites were detected with slight enrichment in coding regions (CDS), and with Um as a dominant $\mathrm{Nm}$ modification (64\% and $78 \%$ of all Nm sites in HeLa and HEK mRNA, respectively). Another manuscript deposited in BioRxiv also goes in the same direction and identifies thousands of Nm sites in yeast mRNA, suggesting that $\mathrm{Nm}$ sites may be prevalent in mRNAs. The presence of these numerous sites needs to be confirmed by orthogonal methods. This may be achieved also by the identification of the enzymes/snoRNAs responsible for these modifications. Some human mRNAs were captured in chimeras with snoRNAs [87], but do not show evidences of 2'-O-methylation, probably reflecting other roles of snoRNAs in mRNA function [104].

\section{Enzymatic mechanisms of 2'-0-methylation}

\section{Protein stand-alone enzymes}

Methyltransferases (MTases) specific to RNA belong to a vast group of MTases that catalyze the transfer of a CH3-group (Me-group) from a methyl donor to a biomolecule [105-107]. The almost universal methyl donor in all three kingdoms of life is S-adenosyl-L-methionine (SAM or AdoMet). There are 6 MTase types 
according to their targets: histones, protein $\mathrm{N}$-terminal aminoacid, DNA, RNA, natural product and non SAM-dependent methyltransferases. This last group uses $\mathrm{N}^{5}, \mathrm{~N}^{10}$-methylenetetrahydrofolate $\left(\mathrm{CH}_{2} \mathrm{H}_{4}\right.$ - folate $)$ as a methyl donor. All MTases share the same core structure of a mixed seven stranded $\beta$-sheets. Five SAMbinding classes of MTases $(I-V)$ differs by the presence of characteristic motifs and the global organization of the protein fold [107]. Although a lot of known MTases, such as DNA-MTases, are in the Class I, most 2'-OMTases belong to the superfamily of SPOUT MTases (class IV). In the past RNA 2'-O-MTases were separated into two groups: Rossman-like fold MTases (RMT) and SPOUT, but recently it has been demonstrated that they share a common evolutionary origin and they all form a single superfamily $[105,108-110]$.

\section{Bacterial tRNA 2'-0-methyltransferases}

Enzymes involved in tRNA 2'-O-methylation are rather well studied in E. coli. Each known position is formed by a specific tRNA MTase. TrmH (or SpoU) is responsible for $\mathrm{Gm} 18$ and was found in the gmk-rpoZ-spoTspoU-recG operon [111,112]. This enzyme is conserved in Gram negative species and in species living in harsh conditions such as T. thermophilus [113]. However, no TrmH homologs were reported for Gram positive species such as Staphylococcus aureus, Lactococcus lactis or Bacillus subtilis. Crystal structures of TrmH bound or not to SAM have been established and by extensive mutagenesis studies, catalytic site and enzyme reaction mechanism have been characterized. Four amino acids of the catalytic site (Asn35, Arg41, Glu124 and Asn152) are involved in tRNA binding. In addition, Asn35 is also responsible for SAM release $[109,111,114]$.

TrmJ (or YfhQ or TrMet5Xm32) is involved in the formation of Cm32 in tRNA ${ }^{\mathrm{Ser}}{ }_{1}$ and tRNA ${ }^{\mathrm{Gln}}{ }_{2}$ [115]. This enzyme also belongs to the SPOUT class of MTases [116]. The 3D structure and catalytic site of $E$. coli TrmJ have been characterized. tRNA recognition by TrmJ involves not only SPOUT domain, but also additional parts of the protein [117]. Characterization of TrmJ from Pseudomonas aeruginosa revealed that, in addition to $\mathrm{Cm} 32$ and Um32, this MTase catalyzes also Am32 formation in tRNA ${ }^{\text {Pro }}$ (GGG) [118].

$\operatorname{TrmL}$ (yibK) is responsible for 2'-O-methylation at position 34 in two E. coli tRNA ${ }^{\text {Leu }}$ (anticodons CAA and UAA). $\mathrm{Cm} 34$ is formed in TRNA ${ }^{\text {Leu }}(C A A)$ and Um34 is introduced in an hypermodified nucleotide in another 5 isoacceptor tRNA ${ }^{\text {Leu }}(\mathrm{cmnm}$ UmAA) [119]. TrmL methylates only pyrimidine residues at position 34 and requires 2-methylthio- $\mathrm{N}^{6}$-isopentenyadenosine $\left(\mathrm{ms}^{2} \mathrm{I}^{6} \mathrm{~A}\right)$ at position 37 for activity [120]. Sequence homology search using $\operatorname{TrmL}$ as a query, revealed homologous proteins in L. lactis and B. subtilis, but not in S. aureus [121].

\section{Archaeal tRNA 2'-0-methyltransferases}

In contrast to bacteria, archaeal species use both stand-alone enzymes and C/D-box small RNA (sRNA) guided machinery for tRNA 2'-O-methylation, sometimes with overlapping substrate and site specificity [122]. The universally conserved $\mathrm{Cm} 32$ and the archaea-specific position $\mathrm{Cm} 56$ are catalyzed by stand-alone archaeal MTases belonging to the SPOUT family.

In Sulfolobus acidocaldarius, 2'-O-methylation at position 32 is catalyzed by a homolog of the bacterial TrmJ. However, while in E. coli TrmJ modifies tRNAs without any specificity for a given nucleotide, its archaeal homolog can act only at the ribose of a cytidine [116]. Enzyme aTrm56 methylates the ribose of a cytidine residue and is found in almost all sequenced archaeal genomes, except for the crenarchaeon Pyrobaculum aerophilum in which $\mathrm{Cm} 56$-forming activity is provided by a C/D-box sRNP [123]. Similarly, Cm34 formation in Haloferax volcanii elongator tRNA ${ }^{\text {Met }}$ is guided by a C/D- box SRNA targeting the tRNA intron-containing 
precursor [124] and Cm34 and Um39 in pre-tRNA ${ }^{\text {Trp }}$ are formed by another C/D- box sRNP machinery [125].

\section{Eukaryotic tRNA 2'-0-methyltransferases}

The formation of the highly conserved Gm18 in S. cerevisiae is catalyzed by Trm3 (encoded by ORF YDL112w). Genetic depletion of Trm3 led to a complete absence of Gm18 in tRNAs, while other 2'-Omethylations in tRNA or rRNA were not affected [126]. Two S. cerevisiae 2'-O-methylations Cm32 and Nm34 present in tRNA anticodon loop share a common MTase Trm7 [45,127] (encoded by YBR061C), that requires a protein partner to specify which position is methylated [128]. When Trm7 is interacting with Trm732 (encoded by YMR259c) $\mathrm{Cm} 32$ is formed, while when Trm7 is associated to Trm734 (or Rtt10), nucleotide at position 34 is methylated [49]. However, $\mathrm{Cm} 32$ and Nm34 seem to be formed by different catalytic mechanisms since a specific mutation in Trm7 abolishes formation of only Gm34 in tRNA ${ }^{\text {Phe }}$ [129]. Formation of Um44 is catalyzed by Trm44 (ORF YPL030w) which is found in metazoans and fungi, but not in plants [46]. Finally, position 4 in S. cerevisiae tRNAs is methylated by Trm13 (encoded by YOL125w) [47] which belongs to Rossmann-fold family of MTases [130] (Figure 5).

In Drosophila, tRNA 2'-O-methylation profile has not been deeply characterized. Only a putative tRNA:(Cm32/Gm34)-2'-O-methyltransferase has been identified by sequence homology, but no experimental validation was performed. As observed in human tRNAs, 2'-O-methyl-ribothymidine (Tm,

5

$\mathrm{m}$ Um) was found to replace ribothymidine in drosophila tRNA and tRNA species [21].

In human, positions of tRNA 2'-O-methylation are mostly known, but the corresponding enzymes were not systematically characterized (Figure 5). Sequence homology search using yeast MTases revealed homologous enzymes for all of them (Supplementary Table 1), but no activity test was performed for these proteins [131]. Only human protein homologous to yeast Trm7 2'-O-MTase was characterized and called FTSJ1. Indeed, human cells with mutations in FTJS1 nearly completely lack both Cm32 and Gm34 [129].

\section{Stand-alone rRNA 2'-O-methyltransferases}

Ribose methylations in E. coli rRNAs (C1402 of the SSU-16S rRNA and G2251, C2498 and U2552 of the LSU$23 \mathrm{~S}$ rRNA) [59] are formed by stand-alone MTases Rsml (YraL), RImB (YfjH), RImM (YgdE), RImE (RrmJ or Ftsj), respectively (Supplementary Table 1) [60,62]. While RImB and RImE belong to the SPOUT family, RImM and Rsml have a Rossman-like fold structure [132]. Crystal structures of RImM-SAM [133], Rsml-SAM-rRNA [134], RImB [135] and RImE [136] were determined and allow a better understanding recognition of their substrates and organization of catalytic domains.

In archaea and eukarya, the implication of stand-alone MTases in rRNA ribose methylation remains an exception. Indeed, this function is mainly insured by C/D-box s(sno)RNPs. Interestingly, a recent report described a newly discovered stand-alone activity of archaeal Fib-Nop5 heterodimer that can perform 2'-Omethylation of SSU-16S and LSU-23S rRNAs in Pyrococcus abyssi [137].

In yeast S. cerevisiae, Spb1 protein was shown to methylate both G2922 and U2921 residues in late $27 \mathrm{~S}$ prerRNA precursor, the latter is also modified by a guide snR52-snoRNP $[138,139]$. Spb1 corresponds to the bacterial RrmJ (specific to U2552 in LSU-23S rRNA). The human homolog of yeast Spb1 is FTSJ3. It was demonstrated that FTSJ3 is involved in pre-rRNA processing via its interaction with NIP7: a trans-acting factor required for eukaryotic ribosome biogenesis [140]. A recent study deposited in BioRxiv claimed that Sbp1 has 2'-O-MTase activity and is responsible for methylation of thousands sites in yeast mRNA, 
suggesting that human FTSJ3 may have the same function.

Interestingly, the yeast enzyme Trm7 which is normally required for 2'-O-methylation at positions 32 and 34 in several tRNAs, has been recently reported to be directly or indirectly involved in methylation of five positions in S. cerevisiae 25S rRNAs: Am649, Cm663, Gm805, Am807 and Um2421, [141]. These positions were found to be significantly hypo-methylated in a $\Delta T r m 7$ mutant. Furthermore, the most affected position, $\mathrm{Cm663}$, was hypo-methylated in mutants lacking Rtt10, one of the two heterodimerization partners for Trm7. The closest homolog of eukaryotic Trm7 is a rRNA:MTase in bacteria [142].

In human mitochondria, three closely related 2'-O-ribose MTases (MRM1, MRM2/FTSJ2, and MRM3/RNMTL1) modify three positions of the peptidyl transferase center of LSU 16S mt-rRNA, Gm1145, Um1369 and Gm1370, respectively (Supplementary Table 2) [91,92,143]. MRM1 and MRM2 have bacterial and yeast homologs, whereas MRM3 appears to have evolved later in higher eukaryotes [92,142]. Defective mitochondrial rRNA methyltransferase MRM2 causes MELAS-like clinical syndrome [144].

In yeast, PET56 is a ribose MTase that modifies the conserved nucleotide G2270 in the peptidyl transferase center of the mitochondrial LSU-21S rRNA. Loss of this modification leads to a defect in assembly of mitochondrial large ribosomal subunits [78]. Mrm2p, which is the ortholog of FtsJ/RrmJ in E. coli, catalyzes the formation of Um2791 in LSU-21S rRNA [142] (Supplementary Table 2).

\section{SiRNA/piRNA/miRNA 2'-O-methylation enzymes}

In Arabidopsis, 2'-O-methylation at the 3'-end of RNA is performed by the RNA methyltransferase Hua Enhancer 1 (HEN1), which methylates both miRNA/miRNA and siRNA/siRNA duplexes with a preference for 21-24 nt RNA duplexes with a 2 nt overhangs $[145,146]$. In contrast to plants, HEN1 homologs in animals act on single-stranded RNAs such as germline piRNAs and Ago2-associated siRNAs (but not Ago1-associated miRNA) as well as tRNA-derived sncRNAs [147] to deposit a 2'-O-methyl group on their 3' termini $[147,148]$. Interestingly, the substrates of HEN1 are quite different between plants and other species and this was recently proposed to be due to a conserved FxPP motif that is essential for substrate recognition [147].

In different organisms, HEN1 mutant phenotypes showed reduction of small RNA and piRNA abundance and pleiotropic developmental defects (for more details, see review of [102]). $3^{\prime}$-end methylation has two major roles: 1 ) to protect small RNAs from $3^{\prime}$-terminal uridylation and 2) to inhibit $3^{\prime}->5^{\prime}$ exonucleolytic degradation [149], thereby maintaining an equilibrium in the levels of small non-coding RNAs. Interestingly, HEN1 homolog is also present in bacteria [150]. Pnkp/Hen1 system adds a methyl group to the 2'-OH group on the original RNA cleavage site and thus prevents it from further cleavage (for review, [151]).

\section{snoRNA (sRNA) guided machinery for ribose methylation}

In archaea and eukaryotes, 2'-O-methylations in rRNA are introduced by one class of structurally and functionally conserved small RNA-protein complexes (named C/D-box sRNPs in archaea) or small nucleolar RNA-protein complexes (named C/D-box snoRNP in eukaryotes) [152-155]. Each C/D-box s(no)RNP is formed by one specific small RNA (sRNA or snoRNA) which targets a specific nucleotide that will be modified and a set of three (in archaea) or four (in eukaryotes) common proteins including one SAMdependent methyltransferase called fibrillarin (Nop1 in yeast). The other protein components of the $\mathrm{s}$ (no)RNP are Nop56, Nop58 (Nop5 in archaea is related to the two proteins) and 15.5K (Snu13p in yeast and L7Ae in Archaea) Figure 6. Many mechanistic studies were carried out in Archaea in order to understand the catalytic mechanism of sRNP-catalyzed ribose methylation. This was made possible because, in contrast to 
their eukaryotic homologs, the methylation C/D-box sRNP complex has a capacity to assemble in vitro [156]. L7Ae binds first to the helix-internal loop-helix structure K-turn of the RNA guide [157]. Then the C-terminal domain of Nop5 binds to the L7Ae-RNA complex, while the N-terminal domain of Nop5 interacts with fibrillarin [158].

The length of C/D-box s(no)RNAs varies from approximately 50 to $300 \mathrm{nts}$, being shorter in Archaea (50-70 nts). The s(no)RNAs are characterized by two well-conserved sequences called $C$ box (RUGAGA) and $D$ box (CUGA) elements located respectively at the $5^{\prime}$ and $3^{\prime}$ extremities of the RNA and less conserved internal ones called $C^{\prime}$ and $D^{\prime}$. These motifs fold into a kink-turn structure (C/D-box) and a kink-loop structure ( $C^{\prime} / D^{\prime}$ box) allowing binding of the core proteins and the positioning of fibrillarin for catalysis [159]. By sequence complementarity between the guide sequence and the RNA target, snoRNA guide places the catalytic subunit for methylation. The guide sequence is longer in eukaryotes than in archaea, 10-21 nts and 8-12 nts in length, respectively. It is possible that base pairing rules for C/D-box sno(s)RNAs may be modulated under stress conditions, allowing modification at additional sites in RNA.

Unlike eukaryotes, archaeal C/D-box sRNP particles combine two methylation events at the same time on two distinct substrate RNA positions [160]. This particularity has no known explanation yet, but this arrangement is probably allowing coordination of methylation states of the two sites [161].

Archaea C/D-box sRNAs are highly abundant and ensure folding and stabilization of RNA molecules through modification of numerous nucleotides. In order to identify 2'-O-methylation targets of C/D-box sRNAs in archaea, 18 different C/D box sRNAs were first captured by co-immunoprecipitation with fibrillarin and Nop5 from Sulfolobus acidocaldarius [156]. Thereafter a global profiling of small RNAs from archaeal model organisms has been obtained using global RNA-Seq technology and numerous C/D box sRNA sequences were experimentally verified $[162,163]$.

In yeast, except for the residue $25 \mathrm{~S}-\mathrm{Gm} 2922$ which is methylated both by the stand-alone methyltransferase Sbp1 and a snoRNP, all other 2'-O-methylations are essentially carried out by 47 C/D-box snoRNPs each directing the methylation of one or two positions [154]. Two snoRNAs, U24 and snR40, have been found to target 3 positions each [74]. Conversely, one rRNA position can be methylated by more than one snoRNP.

To generate an updated catalog of human C/D-box snoRNAs that direct 2'-O-ribose methylation in human rRNA, a high-throughput variant of the reverse-transcriptase-based method was developed (termed RimSeq) [164].

In conclusion, 2'-O-methylation in tRNA is mostly done by protein stand-alone enzymes, except some specific archaeal species which are modified using C/D-box sRNA guides. In contrast, rRNA 2'-O-methylation is insured by stand-alone enzymes only in bacteria and eukaryotic organelles, while the same type of modification is formed in archaeal and eukaryotic rRNA by snoRNA-guided machinery.

\section{Dynamics of RNA 2'-O-methylation}

Dynamics of RNA methylation as well as incomplete methylation levels in different RNA species, depending on cell origin or tissue, were long standing observations already from early studies in 60's to 80's $[22,23,165]$. Various differentially modified tRNA species were isolated from different sources, but their relevance to any biological function was not established. Only very recently this idea came back to limelight and several studies clearly established that modification profile of tRNAs [166-168] and also rRNAs [81,169] can be modulated during stress, or depending on the physiological status of the cell. 
These observations experimentally demonstrate fine tuning of the translational machinery in response to stress and even precise modulation of specific mRNA translation in function of the RNA modification profile. 2'-O-Methylations, together with other modified nucleotides, present in tRNAs and rRNAs play an important role in such adaptation mechanisms.

Novel RNP complexes termed regulatory RNPs (regRNPs) have been described to provide a mechanism by which ribosome heterogeneity is accomplished [170]. Indeed, three C/D-box scaRNA (2, 9 and 17) which naturally guide the 2'-O-methylations of specific sites on U2, U4 and U12 snRNAs, respectively, give rise to stable, nucleolus enriched RNA fragments [171] that can impact the activity of snoRNPs by base pairing with several different snoRNAs. At least three 2'-O-methylation sites in human rRNA (28S-Gm3923, 18S-Um1804 and 18S-Am484) were shown to be differentially modified in endogenous ribosomes with a variability $>25 \%$ $[37,79,172]$ and are predicted to be regulated via interaction of regRNP 2,9 and 17 with HBII82B, snoRD20 and snoRD16, respectively. It is the case of regRNP17 that impacts the level of 18S-Am484 in rRNA via interaction with snoRD16, by disrupting snoRD16/18S rRNA interaction [170].

\section{Biological functions of 2'-O-methylated residues}

The exact biological roles and functions of ribose methylation in RNA are still to a large extent unknown. It was demonstrated that Nm nucleotides are involved in RNA stability, and also play a role in more subtle functions such as translational modulation and are implicated in immune evasion mechanisms.

\section{Physical properties of 2'-O-methylation}

The presence of methyl group at the ribose $2^{\prime}-\mathrm{OH}$ considerably affects the physico-chemical properties of the modified nucleoside(tide). Formally, base-pairing of 2'-O-Me nucleotides is not directly affected, even if stabilization of the typical A-type RNA helix is observed $[30,173]$. In contrast, the hydrogen bonding, typical for unmodified $2^{\prime}-\mathrm{OH}$ of the ribose, is abolished by methylation, as well as the nucleophilic character of the O2'. This leads to highly increased stability of 2'-O-methylated RNA against alkaline (and even enzymatic) hydrolysis $[174,175]$. In addition, the absence of the proton at $2^{\prime}-\mathrm{OH}$ negatively affects protein binding, as was demonstrated for components of mRNA polyadenylation machinery [176] and may also be the case for exon-junction complex deposition [177,178]. Ribose methylation also affects the RNA-DNA duplex formation, this property is used to limit off-target effects of siRNAs (see for example [179]).

\section{RNA stabilization}

Post-transcriptional modifications of RNA have been shown to exert noticeable effects on stability of hyperthermophilic archaeal tRNAs [180]. The association of both base modification and 2'-O-methylation at the same nucleotide, which is the case of nucleosides $\mathrm{ac}^{4} \mathrm{Cm}$ and $\mathrm{m}^{2} \mathrm{Gm}$, unique to the archaeal hyperthermophiles, seems to have additive effects to confer conformational stability essential for tRNA function [173]. This stabilization is particularly important for hyperthermophilic archaea to counterbalance RNA unfolding at elevated growth temperatures. Interestingly, tRNAs from mesophilic archaea, which grow at moderate temperatures, generally have only one of these ribose and base modifications. A relationship between the $B$. stearothermophilus growth temperature and in vivo tRNA methylation profile was established. It was shown that the nature of the modified nucleotides in tRNA remains similar between $50^{\circ} \mathrm{C}$ and $70^{\circ} \mathrm{C}$, but the rate of global methylation increases 1.4 times essentially due to 2'-O-methylation [181]. As at $70^{\circ} \mathrm{C}$ the global tRNA structure is in an open form, RNA might be more accessible to respective 
MTases, that would serve as a kind of protection to prevent tRNA degradation by nucleases.

Ribosomal RNA from bacterial and archaeal hyperthermophiles shows the same tendency of an increased level of 2'-O-ribose methylation proportional to the growth temperature. This suggests a potential role of these rRNA modifications in RNA stabilization under extreme conditions. The first post-transcriptional modification map for the $16 \mathrm{~S}$ rRNA including identity and sequence location of modified residues was described for the bacterial thermophile, $T$. thermophilus grown at $75^{\circ} \mathrm{C}$ [69]. Similarly, archaea that are growing at higher temperatures contain more guide C/D-box sRNAs and, in consequence, more 2'-Omethylations [71,182,183].

Interestingly, a protective effect of 2'-O-methylation against age-related neurodegenerative events has been observed in Drosophila. With age, miRNAs containing 2'-0-methylation at their 3 '-end are preferentially loaded by Ago2 and thus are protected from degradation [184].

\section{Resistance determinant for antibiotics}

Antibiotics targeting the ribosome principally interact with the central loop of the 23S rRNA domain $V$ in the $50 S$ subunit, this interaction has been shown to directly inhibit peptidyl transferase activity and, in consequence, to reduce protein synthesis [185]. To overcome this effect, bacteria have developed various strategies counteracting the effects of antibiotics. One of the strategies used by bacteria is to mutate their rRNA, or, as an alternative, to introduce a methyl group directly at the nucleotides implicated in interaction with the drug/antibiotic [186]. Indeed, it is expected that chemical changes of the RNA constituting the drug binding site can directly influence the strength of binding to the ribosomes $[187,188]$. The first evidence of the involvement of rRNA ribose methylation in antibiotic resistance was brought already in 1979 by the study of thiostrepton producing soil bacteria S. azureus [32]. Thiostrepton is an antibiotic that inhibits bacterial protein synthesis by binding to the $50 \mathrm{~S}$ subunit. To prevent its death $S$. azureus expresses a specific rRNA:2'-O-MTase able to methylate adenosine A1067 (E. coli ribosome numbering) in the 23S rRNA, presumably during $50 \mathrm{~S}$ subunit assembly, and thus prevents thiostrepton binding $[32,189]$.

More recently, by biochemical in vitro experiments and mass spectrometry, it was demonstrated that the rRNA:MTase AviRb which provides avilomycin resistance to the producer strain Streptomyces viridochromogenes Tü57, 2'-O-methylates position U2479 in the 23S rRNA [190].

Another example is given by $\mathrm{Cfr}$ (chloramphenicol-florfenicol resistance) protein which is a rRNA:MTase homologous to a protein superfamily called Radical SAM [191] that targets nucleotide LSU-23S A2503 likely on the ribose and inhibits ribose methylation at nucleotide C2498, thereby causing resistance to chloramphenicol, florfenicol and clindamycin [192]. Nucleotide A2503 is already known to be methylated to $\mathrm{m}^{2} \mathrm{~A}$, but surprisingly, primer extension experiments showed that the stop at $\mathrm{m}^{2} \mathrm{~A} 2503$ is apparently also dNTP concentration-dependent, indicating 2'-O-ribose methylation.

Global screening of rRNA 2'-O-methylation functions in S. cerevisiae with deletion of 20 individual C/D-box snoRNA genes revealed that the loss of individual methylated sites affects adaptation to stress conditions, as well as to intraribosomal antibiotics binding [193]. For the moment, underlying molecular mechanisms affecting stress adaptation remain unclear, but one can imagine enhanced selective translation of stressrelated mRNAs.

\section{$R N A$ repair to counteract ribotoxins}

HEN1 is adding a 2'-O-methyl group at the 3'-end of small RNA in plants and animals. Interestingly, HEN1 
homolog was also found in bacteria where it associates to a protein phosphatase called Pnkp. Bacterial complex Pnkp/Hen1 is able to repair tRNAs cleaved by ribotoxins [150]. The bacterial Pnkp/Hen1 system in addition to other RNA repair system is able to add an extra methyl group to the $2^{\prime}-\mathrm{OH}$ group on the original RNA cleavage site, therefore preventing the repaired RNA from new cleavage at the site of repair (for review, [151]).

\section{Functions of 2'-O-methylation in mRNA splicing and translation}

Eukaryotic splicing machinery is sensitive to the methylation status of both snRNAs and mRNAs. Injection of unmodified U2 snRNA into U2-depleted Xenopus oocytes does not rescue splicing, indicating that U2 snRNA modifications, including 102 '-O-methylations are essential [100]. Later, the region required for U2 snRNP assembly was narrowed down to 20 first $5^{\prime}$-terminal nucleotides containing three pseudouridines and $52^{\prime}$ O-methylations [194]. However, the exact nature of essential residue(s) remains unclear. Artificial insertion of 2'-O-me at the mRNA branch point in Xenopus oocytes activates cryptic branch points in mRNA, thus changing splicing pattern. If no cryptic branch points are present in vicinity, splicing is prevented, even if mRNA is still assembled into pre-catalytic spliceosome [195].

2'-O-methylated residues in mRNAs play different functions depending on their proximity or not to the cap. For instance, it was shown that nucleotide N1 methylation serves as a molecular signature of "self" and thus many viruses produce Cap1-mRNA through the action of host or virally encoded MTases $[196,197]$, thereby escaping from detection by the immune system [198]. In contrast, mRNAs that do not contain any 2'-Omethylation close to the cap are marked as "non-self" and trigger type I IFN response. This mechanism is driven in part by the IFIT proteins (IFN-induced protein with tetratricopeptide repeats-1) which were shown to be effectors of the host immune innate response by selectively inhibiting translation of viral mRNAs [199]. Indeed, X-ray structural analysis recently revealed that these proteins specifically recognize foreign capped mRNAs that do not contain 2'-O-methylated residues and bind to the cap and four additional nucleotides thereby competing with the translation initiation factor elF4F [199]. The RNA sensor MDA5 is also probably involved in the recognition of viral RNAs that do not contain 2'-O-methylated residues [200].

Recently, numerous internal 2'-O-methylation sites were discovered within the human mRNA coding regions and may affect translation either by changing tRNA-mRNA or mRNA-ribosome interactions, resulting in altered dynamics of translation elongation. The first piece of evidence came from an elegant in vitro study where the authors showed that the presence of a 2'-O-methylated mRNA codon decreased translation efficiency, especially when this modification is present at the second position of a codon [201]. This was further confirmed by both single-molecule and bulk kinetic methods, which showed that decrease in translation efficiency is not due to disruption of codon-anticodon RNA-duplex formation, but because it impairs efficient decoding of the modified codon and results in excessive rejection of cognate tRNA during proofreading. Therefore, the presence of 2'-O-methylations in some mRNAs may selectively decrease translation elongation [202].

\section{Importance of 2'-O-methylations for immunostimulation/suppression}

In the field of innate immunity, Toll-like receptors (TLRs) play a crucial role. They recognize microbial associated molecular patterns (MAMPs) and thus activate immune cells. TLR3, 7, 8, 9 and 13 (mouse specific) are known to be activated by nucleic acids. Indeed, TLR3 is specific for double stranded RNA, mouse TLR13 for bacterial 23S rRNA and TLR 9 for unmethylated CpG-DNA. Moreover, TLR7 and TLR8 are 
activated by single stranded RNA of bacterial origin. In humans, TLR7 is expressed only in plasmacytoid dendritic and B cells and induces the production of type I interferon such as IFN- $\alpha$, whereas TLR8 is found in monocytes, myeloid dendritic cells and regulatory $T$ cells and its activation leads the production of cytokines [203]. The innate immune system is able to make a difference between "self" and "non-self" RNA molecules due to specific RNA modifications, spatial restrictions and sequence positions in nucleic acids. It is now well established that 2'-O-methylations act as immunosuppressors. In vitro studies showed that 2'-Omethylations incorporated in in vitro RNA transcripts, siRNA or 18S rRNA prevent TLR activation [203,204]. In fact, in native RNA, it was demonstrated that Gm18 in bacterial E. coli tRNA is responsible for escape from the immune response and that bacterial tRNA ${ }^{\text {Tyr }}$ plays a major role $[205,206]$. The molecular mechanism of immunosupression is still poorly understood. 2'-O-methylated tRNA is a TLR7 antagonist [207] with a recognition pattern of 2 nucleotides including $\mathrm{Gm} 18$ and its downstream neighboring nucleotide [208]. In addition, it was shown that 2'-O-methylation acts as an inhibitor for TLR7, but not for TLR8 [203]. However, other bacterial species that lack Gm18, such as Gram positive strains (e.g. S. aureus) also inhibit TLR7 response. This shows that 2'-O-methylations at other positions in tRNA may also have immunosuppression properties [206].

\section{2'-O-methylations in cancer and development}

Importance of rRNA 2'-O-methylations was established by suppression of snoRNA expression by morpholino antisense oligonucleotides in zebrafish model. Suppression of U26, U44 and U78 snoRNAs (corresponding to 28S-Am398, 18S-Am163 and 28S-Gm3745) reduces rRNA modification at the corresponding sites and led to severe morphological defects and embryonic lethality, suggesting the essential role of those rRNA 2'-Omethylations in vertebrate development [209]. It was recently shown that increased levels of C/D box snoRNA/snoRNP correlated with increased 2'-O-methylation in rRNA contribute to leukaemogenesis [210], probably through increased protein synthesis and impairment of translation fidelity. Therefore, these variations of 2'-O-methylation levels of rRNA contribute to ribosome heterogeneity. In parallel, impairment of Fibrillarin in human cells shows that it correlates with a global 2'-O-methylation rRNA decrease perturbing translation fidelity $[80,81]$. These accumulating evidences show that controlling 2 '-Omethylation levels of rRNA probably may play a key role in ribosome heterogeneity and cancer progression and outcome. Further studies will be necessary to decipher how 2'-O-methylation levels of rRNA tightly regulate cell's fate.

\section{Conclusion}

RNA modifications play an essential role in gene expression regulation, by altering and fine tuning of mRNA, rRNA, tRNA and ncRNA properties. Despite the decades of considerable efforts, our understanding of RNA modification functions remains incomplete. Recent studies aiming to precisely locate RNA modifications and specifically RNA 2'-O-methylations now bring new insights in the field, providing a solid basis for future development. The ultimate step is the precise mapping of such residues in representative cellular RNAs and further understanding of physiological properties of post-transcriptional RNA alterations.

\section{Acknowledgments:}

Y.M was supported by ANR-DFG grant HTRNA-Mod ANR-13-ISV8-0001 and Research funds from Lorraine Région (France). This work was performed in the COST EPITRAN (CA16120) framework. 


\section{Bibliography}

[1] M. Helm, Y. Motorin, Detecting RNA modifications in the epitranscriptome: predict and validate, Nat. Rev. Genet. 18 (2017) 275-291. doi:10.1038/nrg.2016.169.

[2] X. Li, X. Xiong, C. Yi, Epitranscriptome sequencing technologies: decoding RNA modifications, Nat. Methods. 14 (2016) 23-31. doi:10.1038/nmeth.4110.

[3] S. Schwartz, Cracking the epitranscriptome, RNA N. Y. N. 22 (2016) 169-174. doi:10.1261/rna.054502.115.

[4] S. Schwartz, Y. Motorin, Next-generation sequencing technologies for detection of modified nucleotides in RNAs, RNA Biol. 14 (2017) 1124-1137. doi:10.1080/15476286.2016.1251543.

[5] F. Baskin, C.A. Dekker, A rapid and specific assay for sugar methylation in ribonucleic acid, J. Biol. Chem. 242 (1967) 5447-5449.

[6] P.B. Moore, Methylation of messenger RNA in Escherichia coli, J. Mol. Biol. 18 (1966) 38-47.

[7] J.L. Nichols, B.G. Lane, N-4-methyl-2'-O-methyl cytidine and other methyl-substituted nucleoside constituents of Escherichia coli ribosomal and soluble RNA, Biochim. Biophys. Acta. 119 (1966) 649651.

[8] J.L. Nichols, B.G. Lane, In vitro O2'-methylation of sugars in E. coli RNA. II. Methylation of ribosomal and transfer RNA by homologous methylases in crude cell-free extracts and particulate suspensions from a relaxed mutant of E. coli, Can. J. Biochem. 46 (1968) 1487-1495.

[9] M.L. Gefter, The in vitro synthesis of 2'-omethylguanosine and 2-methylthio 6N (gamma,gamma, dimethylallyl) adenosine in transfer RNA of Escherichia coli, Biochem. Biophys. Res. Commun. 36 (1969) 435-441.

[10] B.G. Lane, T. Tamaoki, Methylated bases and sugars in 16-S and 28-S RNA from L cells, Biochim. Biophys. Acta. 179 (1969) 332-340.

[11] R.Y. Lau, B.G. Lane, The sequence distribution of O-2'-methylribose in yeast ribosomal RNA, Can. J. Biochem. 49 (1971) 431-436.

[12] J.L. Nichols, B.G. Lane, In vivo incorporation of methyl groups into the ribose of Escherichia coli ribosomal RNA, J. Mol. Biol. 30 (1967) 477-489.

[13] I. Svensson, G. Björk, W. Björk, K.E. Johansson, A. Johansson, Evidence for enzymatic methylation in vitro of the ribose moiety of RNA, Biochem. Biophys. Res. Commun. 31 (1968) 216-221.

[14] G.R. Björk, I. Svensson, Studies on microbial RNA. Fractionation of tRNA methylases from Saccharomyces cerevisiae, Eur. J. Biochem. 9 (1969) 207-215.

[15] I. Grummt, U. Loening, J.M. Slack, Methylation of ribosomal-precursor RNA, synthesized in vitro, by isolated rat-liver nucleoli, Eur. J. Biochem. 59 (1975) 313-318.

[16] T.W. Munns, H.F. Sims, Methylation and processing of transfer ribonucleic acid in mammalian and bacterial cells, J. Biol. Chem. 250 (1975) 2143-2149.

[17] R.C. Brand, J. Klootwijk, T.J. Van Steenbergen, A.J. De Kok, R.J. Planta, Secondary methylation of yeast ribosomal precursor RNA, Eur. J. Biochem. 75 (1977) 311-318.

[18] D.G. Hughes, B.E. Maden, The pseudouridine contents of the ribosomal ribonucleic acids of three vertebrate species. Numerical correspondence between pseudouridine residues and 2'-O-methyl groups is not always conserved, Biochem. J. 171 (1978) 781-786.

[19] C.C. Hsuchen, D.T. Dubin, Methylation patterns of mycoplasma transfer and ribosomal ribonucleic acid, J. Bacteriol. 144 (1980) 991-998.

[20] B. Vold, Modified nucleosides of Bacillus subtilis transfer ribonucleic acids, J. Bacteriol. 127 (1976) 258-267.

[21] B.N. White, Studies on lysine, glutamine and glutamic acid tRNAs from Drosophila, Biochim. Biophys. Acta. 395 (1975) 322-328.

[22] G.L. Viale, Overmethylated t-RNAs in human gliomas, Riv. Neurobiol. 15 (1969) 505-516.

[23] H. Rogg, P. Müller, G. Keith, M. Staehelin, Chemical basis for brain-specific serine transfer RNAs, Proc. Natl. Acad. Sci. U. S. A. 74 (1977) 4243-4247.

[24] T.S. Ro-Choi, Y.C. Choi, D. Henning, J. McCloskey, H. Busch, Nucleotide sequence of U-2 ribonucleic 
acid. The sequence of the 5'-terminal oligonucleotide, J. Biol. Chem. 250 (1975) 3921-3928.

[25] K. Dimock, C.M. Stoltzfus, Processing and function of undermethylated chicken embryo fibroblast mRNA, J. Biol. Chem. 254 (1979) 5591-5594.

[26] W.L. Heckle, R.G. Fenton, T.G. Wood, C.G. Merkel, J.B. Lingrel, Methylated nucleosides in globin mRNA from mouse nucleated erythroid cells, J. Biol. Chem. 252 (1977) 1764-1770.

[27] J.L. Nichols, L. Welder, The modified nucleotide constituents of human prostatic cancer cell (MA-160) poly(A)-containing RNA, Biochim. Biophys. Acta. 608 (1980) 1-18.

[28] A.J. Ouellette, D. Frederick, R.A. Malt, Methylated messenger RNA in mouse kidney, Biochemistry. 14 (1975) 4361-4367.

[29] M.S. Khan, B.E. Maden, Conformation of methylated sequences in HeLa cell 18-S ribosomal RNA: nuclease S1 as a probe, Eur. J. Biochem. 84 (1978) 241-250.

[30] P. Prusiner, N. Yathindra, M. Sundaralingam, Effect of ribose $\mathrm{O}\left(2^{\prime}\right)$-methylation on the conformation of nucleosides and nucleotides, Biochim. Biophys. Acta. 366 (1974) 115-123.

[31] E. Cundliffe, Mechanism of resistance to thiostrepton in the producing-organism Streptomyces azureus, Nature. 272 (1978) 792-795.

[32] E. Cundliffe, J. Thompson, Ribose methylation and resistance to thiostrepton, Nature. 278 (1979) 859-861.

[33] U. Birkedal, M. Christensen-Dalsgaard, N. Krogh, R. Sabarinathan, J. Gorodkin, H. Nielsen, Profiling of ribose methylations in RNA by high-throughput sequencing, Angew. Chem. Int. Ed Engl. 54 (2015) 451-455. doi:10.1002/anie.201408362.

[34] V. Marchand, F. Blanloeil-Oillo, M. Helm, Y. Motorin, Illumina-based RiboMethSeq approach for mapping of 2'-O-Me residues in RNA, Nucleic Acids Res. 44 (2016) e135. doi:10.1093/nar/gkw547.

[35] V. Marchand, F. Pichot, K. Thüring, L. Ayadi, I. Freund, A. Dalpke, M. Helm, Y. Motorin, NextGeneration Sequencing-Based RiboMethSeq Protocol for Analysis of tRNA 2'-O-Methylation, Biomolecules. 7 (2017). doi:10.3390/biom7010013.

[36] V. Marchand, L. Ayadi, A. El Hajj, F. Blanloeil-Oillo, M. Helm, Y. Motorin, High-Throughput Mapping of 2'-O-Me Residues in RNA Using Next-Generation Sequencing (Illumina RiboMethSeq Protocol), Methods Mol. Biol. Clifton NJ. 1562 (2017) 171-187. doi:10.1007/978-1-4939-6807-7_12.

[37] D. Incarnato, F. Anselmi, E. Morandi, F. Neri, M. Maldotti, S. Rapelli, C. Parlato, G. Basile, S. Oliviero, High-throughput single-base resolution mapping of RNA 2'-O-methylated residues, Nucleic Acids Res. 45 (2017) 1433-1441. doi:10.1093/nar/gkw810.

[38] Y. Zhu, S.P. Pirnie, G.G. Carmichael, High-throughput and site-specific identification of 2'-Omethylation sites using ribose oxidation sequencing (RibOxi-seq), RNA N. Y. N. 23 (2017) 1303-1314. doi:10.1261/rna.061549.117.

[39] Q. Dai, S. Moshitch-Moshkovitz, D. Han, N. Kol, N. Amariglio, G. Rechavi, D. Dominissini, C. He, Nmseq maps 2'-O-methylation sites in human mRNA with base precision, Nat. Methods. 14 (2017) 695698. doi:10.1038/nmeth.4294.

[40] P. Boccaletto, M.A. Machnicka, E. Purta, P. Piatkowski, B. Baginski, T.K. Wirecki, V. de Crécy-Lagard, R. Ross, P.A. Limbach, A. Kotter, M. Helm, J.M. Bujnicki, MODOMICS: a database of RNA modification pathways. 2017 update, Nucleic Acids Res. 46 (2018) D303-D307. doi:10.1093/nar/gkx1030.

[41] R.S. Brown, J.R. Rubin, D. Rhodes, H. Guilley, A. Simoncsits, G.G. Brownlee, The nucleoside sequence of tyrosine tRNA from Bacillus stearothermophilus, Nucleic Acids Res. 5 (1978) 23-36.

[42] N. Takeda, M. Nakamura, H. Yoshizumi, A. Tatematsu, Detection of ribose-methylated nucleotides in Pyrodictium occultum tRNA by liquid chromatography--frit-fast atom bombardment mass spectrometry, J. Chromatogr. B Biomed. Appl. 660 (1994) 223-233.

[43] M. Kuratani, Y. Bessho, M. Nishimoto, H. Grosjean, S. Yokoyama, Crystal structure and mutational study of a unique SpoU family archaeal methylase that forms 2'-O-methylcytidine at position 56 of tRNA, J. Mol. Biol. 375 (2008) 1064-1075. doi:10.1016/j.jmb.2007.11.023.

[44] M.-H. Renalier, N. Joseph, C. Gaspin, P. Thebault, A. Mougin, The Cm56 tRNA modification in archaea is catalyzed either by a specific 2'-O-methylase, or a C/D sRNP, RNA N. Y. N. 11 (2005) 1051-1063. doi:10.1261/rna.2110805.

[45] L. Droogmans, H. Grosjean, 2'-O-methylation and inosine formation in the wobble position of 
anticodon-substituted tRNA-Phe in a homologous yeast in vitro system, Biochimie. 73 (1991) 10211025.

[46] L. Kotelawala, E.J. Grayhack, E.M. Phizicky, Identification of yeast tRNA Um(44) 2'-Omethyltransferase (Trm44) and demonstration of a Trm44 role in sustaining levels of specific tRNA(Ser) species, RNA N. Y. N. 14 (2008) 158-169. doi:10.1261/rna.811008.

[47] M.L. Wilkinson, S.M. Crary, J.E. Jackman, E.J. Grayhack, E.M. Phizicky, The 2'-O-methyltransferase responsible for modification of yeast tRNA at position 4, RNA N. Y. N. 13 (2007) 404-413. doi:10.1261/rna.399607.

[48] M.P. Guy, E.M. Phizicky, Conservation of an intricate circuit for crucial modifications of the tRNAPhe anticodon loop in eukaryotes, RNA N. Y. N. 21 (2015) 61-74. doi:10.1261/rna.047639.114.

[49] M.P. Guy, B.M. Podyma, M.A. Preston, H.H. Shaheen, K.L. Krivos, P.A. Limbach, A.K. Hopper, E.M. Phizicky, Yeast Trm7 interacts with distinct proteins for critical modifications of the tRNAPhe anticodon loop, RNA N. Y. N. 18 (2012) 1921-1933. doi:10.1261/rna.035287.112.

[50] H.J. Gross, M. Simsek, M. Raba, K. Limburg, J. Heckman, U.L. Raj Bhandary, 2'-O-methyl ribothymidine: a component of rabbit liver lysine transfer RNA, Nucleic Acids Res. 1 (1974) 35-43.

[51] M. Sprinzl, N. Dank, S. Nock, A. Schön, Compilation of tRNA sequences and sequences of tRNA genes, Nucleic Acids Res. 19 Suppl (1991) 2127-2171.

[52] J.P. Païs de Barros, G. Keith, C. El Adlouni, A.L. Glasser, G. Mack, G. Dirheimer, J. Desgrès, 2'-O-methyl5 -formylcytidine $(\mathrm{f} 5 \mathrm{Cm})$, a new modified nucleotide at the "wobble" of two cytoplasmic tRNAs Leu (NAA) from bovine liver, Nucleic Acids Res. 24 (1996) 1489-1496.

[53] A.L. Glasser, C. el Adlouni, G. Keith, E. Sochacka, A. Malkiewicz, M. Santos, M.F. Tuite, J. Desgrès, Presence and coding properties of 2'-O-methyl-5-carbamoylmethyluridine (ncm5Um) in the wobble position of the anticodon of tRNA(Leu) (U*AA) from brewer's yeast, FEBS Lett. 314 (1992) 381-385.

[54] K.S. Raviprakash, J.D. Cherayil, 2'-O-methyl-1-methyl adenosine: a new modified nucleoside in ragi (Eleusine coracana) tRNA, Biochem. Biophys. Res. Commun. 121 (1984) 243-248.

[55] J.P. Bachellerie, J. Cavaillé, A. Hüttenhofer, The expanding snoRNA world, Biochimie. 84 (2002) 775790.

[56] D. Piekna-Przybylska, W.A. Decatur, M.J. Fournier, The 3D rRNA modification maps database: with interactive tools for ribosome analysis, Nucleic Acids Res. 36 (2008) D178-183. doi:10.1093/nar/gkm855.

[57] W.A. Decatur, M.J. Fournier, rRNA modifications and ribosome function, Trends Biochem. Sci. 27 (2002) 344-351.

[58] S. Kimura, T. Suzuki, Fine-tuning of the ribosomal decoding center by conserved methylmodifications in the Escherichia coli 16S rRNA, Nucleic Acids Res. 38 (2010) 1341-1352. doi:10.1093/nar/gkp1073.

[59] O.V. Sergeeva, A.A. Bogdanov, P.V. Sergiev, What do we know about ribosomal RNA methylation in Escherichia coli?, Biochimie. 117 (2015) 110-118. doi:10.1016/j.biochi.2014.11.019.

[60] E. Purta, M. O'Connor, J.M. Bujnicki, S. Douthwaite, YgdE is the 2'-O-ribose methyltransferase RImM specific for nucleotide C2498 in bacterial 23S rRNA, Mol. Microbiol. 72 (2009) 1147-1158. doi:10.1111/j.1365-2958.2009.06709.x.

[61] D. Moazed, H.F. Noller, Sites of interaction of the CCA end of peptidyl-tRNA with 23S rRNA, Proc. Natl. Acad. Sci. U. S. A. 88 (1991) 3725-3728.

[62] J.M. Lövgren, P.M. Wikström, The rImB gene is essential for formation of $\mathrm{Gm} 2251$ in 235 rRNA but not for ribosome maturation in Escherichia coli, J. Bacteriol. 183 (2001) 6957-6960. doi:10.1128/JB.183.23.6957-6960.2001.

[63] K. Sirum-Connolly, T.L. Mason, Functional requirement of a site-specific ribose methylation in ribosomal RNA, Science. 262 (1993) 1886-1889.

[64] D.F. Kim, R. Green, Base-pairing between 23S rRNA and tRNA in the ribosomal A site, Mol. Cell. 4 (1999) 859-864.

[65] M. Widerak, R. Kern, A. Malki, G. Richarme, U2552 methylation at the ribosomal A-site is a negative modulator of translational accuracy, Gene. 347 (2005) 109-114. doi:10.1016/j.gene.2004.12.025.

[66] H. Bügl, E.B. Fauman, B.L. Staker, F. Zheng, S.R. Kushner, M.A. Saper, J.C. Bardwell, U. Jakob, RNA 
methylation under heat shock control, Mol. Cell. 6 (2000) 349-360.

[67] T. Caldas, E. Binet, P. Bouloc, A. Costa, J. Desgres, G. Richarme, The FtsJ/RrmJ heat shock protein of Escherichia coli is a 23 S ribosomal RNA methyltransferase, J. Biol. Chem. 275 (2000) 16414-16419. doi:10.1074/jbc.M001854200.

[68] T. Caldas, E. Binet, P. Bouloc, G. Richarme, Translational defects of Escherichia coli mutants deficient in the Um(2552) 23 S ribosomal RNA methyltransferase RrmJ/FTSJ, Biochem. Biophys. Res. Commun. 271 (2000) 714-718. doi:10.1006/bbrc.2000.2702.

[69] R. Guymon, S.C. Pomerantz, P.F. Crain, J.A. McCloskey, Influence of phylogeny on posttranscriptional modification of rRNA in thermophilic prokaryotes: the complete modification map of $16 \mathrm{~S}$ rRNA of Thermus thermophilus, Biochemistry. 45 (2006) 4888-4899. doi:10.1021/bi052579p.

[70] R. Srivastava, K.P. Gopinathan, Ribosomal RNA methylation in Mycobacterium smegmatis SN2, Biochem. Int. 15 (1987) 1179-1188.

[71] P.P. Dennis, V. Tripp, L. Lui, T. Lowe, L. Randau, C/D box sRNA-guided 2'-O-methylation patterns of archaeal rRNA molecules, BMC Genomics. 16 (2015) 632. doi:10.1186/s12864-015-1839-z.

[72] K.H. Seistrup, S. Rose, U. Birkedal, H. Nielsen, H. Huber, S. Douthwaite, Bypassing rRNA methylation by RsmA/Dim1during ribosome maturation in the hyperthermophilic archaeon Nanoarchaeum equitans, Nucleic Acids Res. 45 (2017) 2007-2015. doi:10.1093/nar/gkw839.

[73] J. Klootwijk, R.J. Planta, Analysis of the methylation sites in yeast ribosomal RNA, Eur. J. Biochem. 39 (1973) 325-333.

[74] J. Yang, S. Sharma, P. Kötter, K.-D. Entian, Identification of a new ribose methylation in the $18 \mathrm{~S}$ rRNA of S. cerevisiae, Nucleic Acids Res. 43 (2015) 2342-2352. doi:10.1093/nar/gkv058.

[75] J. Yang, S. Sharma, P. Watzinger, J.D. Hartmann, P. Kötter, K.-D. Entian, Mapping of Complete Set of Ribose and Base Modifications of Yeast rRNA by RP-HPLC and Mung Bean Nuclease Assay, PloS One. 11 (2016) e0168873. doi:10.1371/journal.pone.0168873.

[76] K.E. Sloan, A.S. Warda, S. Sharma, K.-D. Entian, D.L.J. Lafontaine, M.T. Bohnsack, Tuning the ribosome: The influence of rRNA modification on eukaryotic ribosome biogenesis and function, RNA Biol. 14 (2017) 1138-1152. doi:10.1080/15476286.2016.1259781.

[77] M. Taoka, Y. Nobe, Y. Yamaki, Y. Yamauchi, H. Ishikawa, N. Takahashi, H. Nakayama, T. Isobe, The complete chemical structure of Saccharomyces cerevisiae rRNA: partial pseudouridylation of U2345 in 25S rRNA by snoRNA snR9, Nucleic Acids Res. 44 (2016) 8951-8961. doi:10.1093/nar/gkw564.

[78] K. Sirum-Connolly, J.M. Peltier, P.F. Crain, J.A. McCloskey, T.L. Mason, Implications of a functional large ribosomal RNA with only three modified nucleotides, Biochimie. 77 (1995) 30-39.

[79] N. Krogh, M.D. Jansson, S.J. Häfner, D. Tehler, U. Birkedal, M. Christensen-Dalsgaard, A.H. Lund, H. Nielsen, Profiling of 2'-O-Me in human rRNA reveals a subset of fractionally modified positions and provides evidence for ribosome heterogeneity, Nucleic Acids Res. 44 (2016) 7884-7895. doi:10.1093/nar/gkw482.

[80] S. Sharma, V. Marchand, Y. Motorin, D.L.J. Lafontaine, Identification of sites of 2'-O-methylation vulnerability in human ribosomal RNAs by systematic mapping, Sci. Rep. 7 (2017) 11490. doi:10.1038/s41598-017-09734-9.

[81] J. Erales, V. Marchand, B. Panthu, S. Gillot, S. Belin, S.E. Ghayad, M. Garcia, F. Laforêts, V. Marcel, A. Baudin-Baillieu, P. Bertin, Y. Couté, A. Adrait, M. Meyer, G. Therizols, M. Yusupov, O. Namy, T. OhImann, Y. Motorin, F. Catez, J.-J. Diaz, Evidence for rRNA 2'-O-methylation plasticity: Control of intrinsic translational capabilities of human ribosomes, Proc. Natl. Acad. Sci. U. S. A. 114 (2017) 12934-12939. doi:10.1073/pnas.1707674114.

[82] M. Taoka, Y. Nobe, Y. Yamaki, K. Sato, H. Ishikawa, K. Izumikawa, Y. Yamauchi, K. Hirota, H. Nakayama, N. Takahashi, T. Isobe, Landscape of the complete RNA chemical modifications in the human $80 \mathrm{~S}$ ribosome, Nucleic Acids Res. 46 (2018) 9289-9298. doi:10.1093/nar/gky811.

[83] B.E. Maden, Identification of the locations of the methyl groups in $18 \mathrm{~S}$ ribosomal RNA from Xenopus laevis and man, J. Mol. Biol. 189 (1986) 681-699.

[84] B.E. Maden, Locations of methyl groups in $28 \mathrm{~S}$ rRNA of Xenopus laevis and man. Clustering in the conserved core of molecule, J. Mol. Biol. 201 (1988) 289-314.

[85] A. Rebane, H. Roomere, A. Metspalu, Locations of several novel 2'-O-methylated nucleotides in 
human 28S rRNA, BMC Mol. Biol. 3 (2002) 1.

[86] Z. Kiss-László, Y. Henry, J.P. Bachellerie, M. Caizergues-Ferrer, T. Kiss, Site-specific ribose methylation of preribosomal RNA: a novel function for small nucleolar RNAs, Cell. 85 (1996) 1077-1088.

[87] R. Gumienny, D.J. Jedlinski, A. Schmidt, F. Gypas, G. Martin, A. Vina-Vilaseca, M. Zavolan, Highthroughput identification of C/D box snoRNA targets with CLIP and RiboMeth-seq, Nucleic Acids Res. 45 (2017) 2341-2353. doi:10.1093/nar/gkw1321.

[88] R.N. Nazar, T.O. Sitz, H. Busch, Homologies in eukaryotic 5.8S ribosomal RNA, Biochem. Biophys. Res. Commun. 62 (1975) 736-743.

[89] R.N. Nazar, T.O. Sitz, K.D. Somers, Cytoplasmic methylation of mature $5.8 \mathrm{~S}$ ribosomal RNA, J. Mol. Biol. 142 (1980) 117-121.

[90] R.J. Baer, D.T. Dubin, Methylated regions of hamster mitochondrial ribosomal RNA: structural and functional correlates, Nucleic Acids Res. 9 (1981) 323-337.

[91] K.-W. Lee, C. Okot-Kotber, J.F. LaComb, D.F. Bogenhagen, Mitochondrial ribosomal RNA (rRNA) methyltransferase family members are positioned to modify nascent rRNA in foci near the mitochondrial DNA nucleoid, J. Biol. Chem. 288 (2013) 31386-31399. doi:10.1074/jbc.M113.515692.

[92] K.-W. Lee, D.F. Bogenhagen, Assignment of 2'-O-methyltransferases to modification sites on the mammalian mitochondrial large subunit 16 S ribosomal RNA (rRNA), J. Biol. Chem. 289 (2014) 24936-24942. doi:10.1074/jbc.C114.581868.

[93] F. Barneche, C. Gaspin, R. Guyot, M. Echeverría, Identification of 66 box C/D snoRNAs in Arabidopsis thaliana: extensive gene duplications generated multiple isoforms predicting new ribosomal RNA 2'O-methylation sites, J. Mol. Biol. 311 (2001) 57-73. doi:10.1006/jmbi.2001.4851.

[94] S. Higa, N. Maeda, N. Kenmochi, T. Tanaka, Location of 2(')-O-methyl nucleotides in 26S rRNA and methylation guide snoRNAs in Caenorhabditis elegans, Biochem. Biophys. Res. Commun. 297 (2002) 1344-1349.

[95] M.N. Schnare, M.W. Gray, Complete modification maps for the cytosolic small and large subunit rRNAs of Euglena gracilis: functional and evolutionary implications of contrasting patterns between the two rRNA components, J. Mol. Biol. 413 (2011) 66-83. doi:10.1016/j.jmb.2011.08.037.

[96] F. Inesta-Vaquera, V.H. Cowling, Regulation and function of CMTR1-dependent mRNA cap methylation, Wiley Interdiscip. Rev. RNA. 8 (2017). doi:10.1002/wrna.1450.

[97] M. Smietanski, M. Werner, E. Purta, K.H. Kaminska, J. Stepinski, E. Darzynkiewicz, M. Nowotny, J.M. Bujnicki, Structural analysis of human 2'-O-ribose methyltransferases involved in mRNA cap structure formation, Nat. Commun. 5 (2014) 3004. doi:10.1038/ncomms4004.

[98] J. Gu, J.R. Patton, S. Shimba, R. Reddy, Localization of modified nucleotides in Schizosaccharomyces pombe spliceosomal small nuclear RNAs: modified nucleotides are clustered in functionally important regions, RNA N. Y. N. 2 (1996) 909-918.

[99] U.T. Meier, RNA modification in Cajal bodies, RNA Biol. 14 (2017) 693-700. doi:10.1080/15476286.2016.1249091.

[100] Y.T. Yu, M.D. Shu, J.A. Steitz, Modifications of U2 snRNA are required for snRNP assembly and premRNA splicing, EMBO J. 17 (1998) 5783-5795. doi:10.1093/emboj/17.19.5783.

[101] N. Krogh, M. Kongsbak-Wismann, C. Geisler, H. Nielsen, Substoichiometric ribose methylations in spliceosomal snRNAs, Org. Biomol. Chem. 15 (2017) 8872-8876. doi:10.1039/c7ob02317k.

[102] L. Ji, X. Chen, Regulation of small RNA stability: methylation and beyond, Cell Res. 22 (2012) 624636. doi:10.1038/cr.2012.36.

[103] F. Borges, R.A. Martienssen, The expanding world of small RNAs in plants, Nat. Rev. Mol. Cell Biol. 16 (2015) 727-741. doi:10.1038/nrm4085.

[104] E. Sharma, T. Sterne-Weiler, D. O'Hanlon, B.J. Blencowe, Global Mapping of Human RNA-RNA Interactions, Mol. Cell. 62 (2016) 618-626. doi:10.1016/j.molcel.2016.04.030.

[105] S. Boschi-Muller, Y. Motorin, Chemistry enters nucleic acids biology: enzymatic mechanisms of RNA modification, Biochem. Biokhimiia. 78 (2013) 1392-1404. doi:10.1134/S0006297913130026.

[106] P.Z. Kozbial, A.R. Mushegian, Natural history of S-adenosylmethionine-binding proteins, BMC Struct. Biol. 5 (2005) 19. doi:10.1186/1472-6807-5-19.

[107] H.L. Schubert, R.M. Blumenthal, X. Cheng, Many paths to methyltransfer: a chronicle of convergence, 
Trends Biochem. Sci. 28 (2003) 329-335. doi:10.1016/S0968-0004(03)00090-2.

[108] H. Hori, Transfer RNA methyltransferases with a SpoU-TrmD

(SPOUT) fold and their modified nucleosides in tRNA, Biomolecules. 7 (2017). doi:10.3390/biom7010023.

[109] K. Watanabe, O. Nureki, S. Fukai, R. Ishii, H. Okamoto, S. Yokoyama, Y. Endo, H. Hori, Roles of conserved amino acid sequence motifs in the SpoU (TrmH) RNA methyltransferase family, J. Biol. Chem. 280 (2005) 10368-10377. doi:10.1074/jbc.M411209200.

[110] K. Watanabe, O. Nureki, S. Fukai, Y. Endo, H. Hori, Functional categorization of the conserved basic amino acid residues in TrmH (tRNA (Gm18) methyltransferase) enzymes, J. Biol. Chem. 281 (2006) 34630-34639. doi:10.1074/jbc.M606141200.

[111] B.C. Persson, G. Jäger, C. Gustafsson, The spoU gene of Escherichia coli, the fourth gene of the spoT operon, is essential for tRNA (Gm18) 2'-O-methyltransferase activity, Nucleic Acids Res. 25 (1997) 4093-4097.

[112] I. Kumagai, K. Watanabe, T. Oshima, A thermostable tRNA (guanosine-2')-methyltransferase from Thermus thermophilus HB27 and the effect of ribose methylation on the conformational stability of tRNA, J. Biol. Chem. 257 (1982) 7388-7395.

[113] H. Hori, T. Suzuki, K. Sugawara, Y. Inoue, T. Shibata, S. Kuramitsu, S. Yokoyama, T. Oshima, K. Watanabe, Identification and characterization of tRNA $(\mathrm{Gm} 18)$ methyltransferase from Thermus thermophilus HB8: domain structure and conserved amino acid sequence motifs, Genes Cells Devoted Mol. Cell. Mech. 7 (2002) 259-272.

[114] O. Nureki, K. Watanabe, S. Fukai, R. Ishii, Y. Endo, H. Hori, S. Yokoyama, Deep knot structure for construction of active site and cofactor binding site of tRNA modification enzyme, Struct. Lond. Engl. 1993. 12 (2004) 593-602. doi:10.1016/j.str.2004.03.003.

[115] E. Purta, F. van Vliet, K.L. Tkaczuk, S. Dunin-Horkawicz, H. Mori, L. Droogmans, J.M. Bujnicki, The yfhQ gene of Escherichia coli encodes a tRNA:Cm32/Um32 methyltransferase, BMC Mol. Biol. 7 (2006) 23. doi:10.1186/1471-2199-7-23.

[116] J. Somme, B. Van Laer, M. Roovers, J. Steyaert, W. Versées, L. Droogmans, Characterization of two homologous 2'-O-methyltransferases showing different specificities for their tRNA substrates, RNA N. Y. N. 20 (2014) 1257-1271. doi:10.1261/rna.044503.114.

[117] R.-J. Liu, T. Long, M. Zhou, X.-L. Zhou, E.-D. Wang, tRNA recognition by a bacterial tRNA Xm32 modification enzyme from the SPOUT methyltransferase superfamily, Nucleic Acids Res. 43 (2015) 7489-7503. doi:10.1093/nar/gkv745.

[118] J. Jaroensuk, S. Atichartpongkul, Y.H. Chionh, Y.H. Wong, C.W. Liew, M.E. McBee, N. Thongdee, E.G. Prestwich, M.S. DeMott, S. Mongkolsuk, P.C. Dedon, J. Lescar, M. Fuangthong, Methylation at position 32 of tRNA catalyzed by TrmJ alters oxidative stress response in Pseudomonas aeruginosa, Nucleic Acids Res. 44 (2016) 10834-10848. doi:10.1093/nar/gkw870.

[119] A. Benítez-Páez, M. Villarroya, S. Douthwaite, T. Gabaldón, M.-E. Armengod, YibK is the 2'-Omethyltransferase TrmL that modifies the wobble nucleotide in Escherichia coli tRNA(Leu) isoacceptors, RNA N. Y. N. 16 (2010) 2131-2143. doi:10.1261/rna.2245910.

[120] M.-E. Armengod, I. Moukadiri, S. Prado, R. Ruiz-Partida, A. Benítez-Páez, M. Villarroya, R. Lomas, M.J. Garzón, A. Martínez-Zamora, S. Meseguer, C. Navarro-González, Enzymology of tRNA modification in the bacterial MnmEG pathway, Biochimie. 94 (2012) 1510-1520. doi:10.1016/j.biochi.2012.02.019.

[121] P. Puri, C. Wetzel, P. Saffert, K.W. Gaston, S.P. Russell, J.A. Cordero Varela, P. van der Vlies, G. Zhang, P.A. Limbach, Z. Ignatova, B. Poolman, Systematic identification of tRNAome and its dynamics in Lactococcus lactis, Mol. Microbiol. 93 (2014) 944-956. doi:10.1111/mmi.12710.

[122] H. Grosjean, C. Gaspin, C. Marck, W.A. Decatur, V. de Crécy-Lagard, RNomics and Modomics in the halophilic archaea Haloferax volcanii: identification of RNA modification genes, BMC Genomics. 9 (2008) 470. doi:10.1186/1471-2164-9-470.

[123] B. Clouet-d'Orval, C. Gaspin, A. Mougin, Two different mechanisms for tRNA ribose methylation in Archaea: a short survey, Biochimie. 87 (2005) 889-895. doi:10.1016/j.biochi.2005.02.004.

[124] A. Joardar, S.R. Malliahgari, G. Skariah, R. Gupta, 2'-O-methylation of the wobble residue of elongator pre-tRNA(Met) in Haloferax volcanii is guided by a box C/D RNA containing unique features, RNA Biol. 
8 (2011) 782-791. doi:10.4161/rna.8.5.16015.

[125] S.K. Singh, P. Gurha, E.J. Tran, E.S. Maxwell, R. Gupta, Sequential 2'-O-methylation of archaeal pretRNATrp nucleotides is guided by the intron-encoded but trans-acting box C/D ribonucleoprotein of pre-tRNA, J. Biol. Chem. 279 (2004) 47661-47671. doi:10.1074/jbc.M408868200.

[126] J. Cavaillé, F. Chetouani, J.P. Bachellerie, The yeast Saccharomyces cerevisiae YDL112w ORF encodes the putative 2'-O-ribose methyltransferase catalyzing the formation of Gm18 in tRNAs, RNA N. Y. N. 5 (1999) 66-81.

[127] L. Droogmans, E. Haumont, S. de Henau, H. Grosjean, Enzymatic 2'-O-methylation of the wobble nucleoside of eukaryotic tRNAPhe: specificity depends on structural elements outside the anticodon loop, EMBO J. 5 (1986) 1105-1109.

[128] L. Pintard, F. Lecointe, J.M. Bujnicki, C. Bonnerot, H. Grosjean, B. Lapeyre, Trm7p catalyses the formation of two 2'-O-methylriboses in yeast tRNA anticodon loop, EMBO J. 21 (2002) 1811-1820. doi:10.1093/emboj/21.7.1811.

[129] M.P. Guy, M. Shaw, C.L. Weiner, L. Hobson, Z. Stark, K. Rose, V.M. Kalscheuer, J. Gecz, E.M. Phizicky, Defects in tRNA Anticodon Loop 2'-O-Methylation Are Implicated in Nonsyndromic X-Linked Intellectual Disability due to Mutations in FTSJ1, Hum. Mutat. 36 (2015) 1176-1187. doi:10.1002/humu.22897.

[130] K.L. Tkaczuk, Trm13p, the tRNA:Xm4 modification enzyme from Saccharomyces cerevisiae is a member of the Rossmann-fold MTase superfamily: prediction of structure and active site, J. Mol. Model. 16 (2010) 599-606. doi:10.1007/s00894-009-0570-6.

[131] W.L. Towns, T.J. Begley, Transfer RNA methytransferases and their corresponding modifications in budding yeast and humans: activities, predications, and potential roles in human health, DNA Cell Biol. 31 (2012) 434-454. doi:10.1089/dna.2011.1437.

[132] J. Mosquera-Rendón, S. Cárdenas-Brito, J.D. Pineda, M. Corredor, A. Benítez-Páez, Evolutionary and sequence-based relationships in bacterial AdoMet-dependent non-coding RNA methyltransferases, BMC Res. Notes. 7 (2014) 440. doi:10.1186/1756-0500-7-440.

[133] A.S. Punekar, T.R. Shepherd, J. Liljeruhm, A.C. Forster, M. Selmer, Crystal structure of RImM, the 2'Oribose methyltransferase for C2498 of Escherichia coli 23S rRNA, Nucleic Acids Res. 40 (2012) 1050710520. doi:10.1093/nar/gks727.

[134] M. Zhao, H. Zhang, G. Liu, L. Wang, J. Wang, Z. Gao, Y. Dong, L. Zhang, Y. Gong, Structural Insights into the Methylation of C1402 in 16S rRNA by Methyltransferase Rsml, PloS One. 11 (2016) e0163816. doi:10.1371/journal.pone.0163816.

[135] G. Michel, V. Sauvé, R. Larocque, Y. Li, A. Matte, M. Cygler, The structure of the RImB 23S rRNA methyltransferase reveals a new methyltransferase fold with a unique knot, Struct. Lond. Engl. 1993. 10 (2002) 1303-1315.

[136] J. Hager, B.L. Staker, U. Jakob, Substrate binding analysis of the $23 \mathrm{~S}$ rRNA methyltransferase RrmJ, J. Bacteriol. 186 (2004) 6634-6642. doi:10.1128/JB.186.19.6634-6642.2004.

[137] M. Tomkuvienè, J. Ličytè, I. Olendraitè, Z. Liutkevičiūtè, B. Clouet-d'Orval, S. Klimašauskas, Archaeal fibrillarin-Nop5 heterodimer 2'-O-methylates RNA independently of the C/D guide RNP particle, RNA N. Y. N. 23 (2017) 1329-1337. doi:10.1261/rna.059832.116.

[138] C. Bonnerot, L. Pintard, G. Lutfalla, Functional redundancy of Spb1p and a snR52-dependent mechanism for the 2'-O-ribose methylation of a conserved rRNA position in yeast, Mol. Cell. 12 (2003) 1309-1315.

[139] B. Lapeyre, S.K. Purushothaman, Spb1p-directed formation of Gm2922 in the ribosome catalytic center occurs at a late processing stage, Mol. Cell. 16 (2004) 663-669.

doi:10.1016/j.molcel.2004.10.022.

[140] L.G. Morello, P.P. Coltri, A.J.C. Quaresma, F.M. Simabuco, T.C.L. Silva, G. Singh, J.A. Nickerson, C.C. Oliveira, M.J. Moore, N.I.T. Zanchin, The human nucleolar protein FTSJ3 associates with NIP7 and functions in pre-rRNA processing, PloS One. 6 (2011) e29174. doi:10.1371/journal.pone.0029174.

[141] H.-J. Chou, E. Donnard, H.T. Gustafsson, M. Garber, O.J. Rando, Transcriptome-wide Analysis of Roles for tRNA Modifications in Translational Regulation, Mol. Cell. 68 (2017) 978-992.e4. doi:10.1016/j.molcel.2017.11.002. 
[142] L. Pintard, J.M. Bujnicki, B. Lapeyre, C. Bonnerot, MRM2 encodes a novel yeast mitochondrial $21 \mathrm{~S}$ rRNA methyltransferase, EMBO J. 21 (2002) 1139-1147. doi:10.1093/emboj/21.5.1139.

[143] J. Rorbach, P. Boesch, P.A. Gammage, T.J.J. Nicholls, S.F. Pearce, D. Patel, A. Hauser, F. Perocchi, M. Minczuk, MRM2 and MRM3 are involved in biogenesis of the large subunit of the mitochondrial ribosome, Mol. Biol. Cell. 25 (2014) 2542-2555. doi:10.1091/mbc.E14-01-0014.

[144] C. Garone, A.R. D'Souza, C. Dallabona, T. Lodi, P. Rebelo-Guiomar, J. Rorbach, M.A. Donati, E. Procopio, M. Montomoli, R. Guerrini, M. Zeviani, S.E. Calvo, V.K. Mootha, S. DiMauro, I. Ferrero, M. Minczuk, Defective mitochondrial rRNA methyltransferase MRM2 causes MELAS-like clinical syndrome, Hum. Mol. Genet. 26 (2017) 4257-4266. doi:10.1093/hmg/ddx314.

[145] Z. Yang, Y.W. Ebright, B. Yu, X. Chen, HEN1 recognizes 21-24 nt small RNA duplexes and deposits a methyl group onto the 2' OH of the 3' terminal nucleotide, Nucleic Acids Res. 34 (2006) 667-675. doi:10.1093/nar/gkj474.

[146] B. Yu, Z. Yang, J. Li, S. Minakhina, M. Yang, R.W. Padgett, R. Steward, X. Chen, Methylation as a crucial step in plant microRNA biogenesis, Science. 307 (2005) 932-935. doi:10.1126/science.1107130.

[147] L. Peng, F. Zhang, R. Shang, X. Wang, J. Chen, J.J. Chou, J. Ma, L. Wu, Y. Huang, Identification of substrates of the small RNA methyltransferase Hen1 in mouse spermatogonial stem cells and analysis of its methyl-transfer domain, J. Biol. Chem. (2018). doi:10.1074/jbc.RA117.000837.

[148] M.D. Horwich, C. Li, C. Matranga, V. Vagin, G. Farley, P. Wang, P.D. Zamore, The Drosophila RNA methyltransferase, DmHen1, modifies germline piRNAs and single-stranded siRNAs in RISC, Curr. Biol. CB. 17 (2007) 1265-1272. doi:10.1016/j.cub.2007.06.030.

[149] J. Li, Z. Yang, B. Yu, J. Liu, X. Chen, Methylation protects miRNAs and siRNAs from a 3'-end uridylation activity in Arabidopsis, Curr. Biol. CB. 15 (2005) 1501-1507. doi:10.1016/j.cub.2005.07.029.

[150] C.M. Chan, C. Zhou, R.H. Huang, Reconstituting bacterial RNA repair and modification in vitro, Science. 326 (2009) 247. doi:10.1126/science.1179480.

[151] R.H. Huang, Unique 2'-O-methylation by Hen1 in eukaryotic RNA interference and bacterial RNA repair, Biochemistry. 51 (2012) 4087-4095. doi:10.1021/bi300497x.

[152] A.K. Henras, C. Plisson-Chastang, O. Humbert, Y. Romeo, Y. Henry, Synthesis, Function, and Heterogeneity of snoRNA-Guided Posttranscriptional Nucleoside Modifications in Eukaryotic Ribosomal RNAs, The Enzymes. 41 (2017) 169-213. doi:10.1016/bs.enz.2017.03.007.

[153] L. Lestrade, M.J. Weber, snoRNA-LBME-db, a comprehensive database of human H/ACA and C/D box snoRNAs, Nucleic Acids Res. 34 (2006) D158-162. doi:10.1093/nar/gkj002.

[154] T.M. Lowe, S.R. Eddy, A computational screen for methylation guide snoRNAs in yeast, Science. 283 (1999) 1168-1171.

[155] L. Lui, T. Lowe, Small nucleolar RNAs and RNA-guided post-transcriptional modification, Essays Biochem. 54 (2013) 53-77. doi:10.1042/bse0540053.

[156] A.D. Omer, S. Ziesche, H. Ebhardt, P.P. Dennis, In vitro reconstitution and activity of a C/D box methylation guide ribonucleoprotein complex, Proc. Natl. Acad. Sci. U. S. A. 99 (2002) 5289-5294. doi:10.1073/pnas.082101999.

[157] J.F. Kuhn, E.J. Tran, E.S. Maxwell, Archaeal ribosomal protein L7 is a functional homolog of the eukaryotic 15.5kD/Snu13p snoRNP core protein, Nucleic Acids Res. 30 (2002) 931-941.

[158] M. Aittaleb, R. Rashid, Q. Chen, J.R. Palmer, C.J. Daniels, H. Li, Structure and function of archaeal box C/D sRNP core proteins, Nat. Struct. Biol. 10 (2003) 256-263. doi:10.1038/nsb905.

[159] Z. Kiss-László, Y. Henry, T. Kiss, Sequence and structural elements of methylation guide snoRNAs essential for site-specific ribose methylation of pre-rRNA, EMBO J. 17 (1998) 797-807. doi:10.1093/emboj/17.3.797.

[160] S.L. Reichow, T. Hamma, A.R. Ferré-D’Amaré, G. Varani, The structure and function of small nucleolar ribonucleoproteins, Nucleic Acids Res. 35 (2007) 1452-1464. doi:10.1093/nar/gkl1172.

[161] A. Graziadei, P. Masiewicz, A. Lapinaite, T. Carlomagno, Archaea box C/D enzymes methylate two distinct substrate rRNA sequences with different efficiency, RNA N. Y. N. 22 (2016) 764-772. doi:10.1261/rna.054320.115.

[162] L. Randau, RNA processing in the minimal organism Nanoarchaeum equitans, Genome Biol. 13 (2012) R63. doi:10.1186/gb-2012-13-7-r63. 
[163] A.A.H. Su, V. Tripp, L. Randau, RNA-Seq analyses reveal the order of tRNA processing events and the maturation of C/D box and CRISPR RNAs in the hyperthermophile Methanopyrus kandleri, Nucleic Acids Res. 41 (2013) 6250-6258. doi:10.1093/nar/gkt317.

[164] H. Jorjani, S. Kehr, D.J. Jedlinski, R. Gumienny, J. Hertel, P.F. Stadler, M. Zavolan, A.R. Gruber, An updated human snoRNAome, Nucleic Acids Res. 44 (2016) 5068-5082. doi:10.1093/nar/gkw386.

[165] E. Randerath, A.S. Gopalakrishnan, R.C. Gupta, H.P. Agrawal, K. Randerath, Lack of a specific ribose methylation at guanosine 17 in Morris hepatoma 5123D tRNASer1IGA, Cancer Res. 41 (1981) 28632867.

[166] C.T.Y. Chan, M. Dyavaiah, M.S. DeMott, K. Taghizadeh, P.C. Dedon, T.J. Begley, A quantitative systems approach reveals dynamic control of tRNA modifications during cellular stress, PLoS Genet. 6 (2010) e1001247. doi:10.1371/journal.pgen.1001247.

[167] Y.H. Chionh, M. McBee, I.R. Babu, F. Hia, W. Lin, W. Zhao, J. Cao, A. Dziergowska, A. Malkiewicz, T.J. Begley, S. Alonso, P.C. Dedon, tRNA-mediated codon-biased translation in mycobacterial hypoxic persistence, Nat. Commun. 7 (2016) 13302. doi:10.1038/ncomms13302.

[168] L. Endres, P.C. Dedon, T.J. Begley, Codon-biased translation can be regulated by wobble-base tRNA modification systems during cellular stress responses, RNA Biol. 12 (2015) 603-614. doi:10.1080/15476286.2015.1031947.

[169] M. Buchhaupt, S. Sharma, S. Kellner, S. Oswald, M. Paetzold, C. Peifer, P. Watzinger, J. Schrader, M. Helm, K.-D. Entian, Partial methylation at Am100 in 18S rRNA of baker's yeast reveals ribosome heterogeneity on the level of eukaryotic rRNA modification, PloS One. 9 (2014) e89640. doi:10.1371/journal.pone.0089640.

[170] A.R. Poole, I. Vicino, H. Adachi, Y.-T. Yu, M.D. Hebert, Regulatory RNPs: a novel class of ribonucleoproteins that potentially contribute to ribosome heterogeneity, Biol. Open. 6 (2017) 13421354. doi:10.1242/bio.028092.

[171] K.T. Tycowski, A. Aab, J.A. Steitz, Guide RNAs with 5' caps and novel box C/D snoRNA-like domains for modification of snRNAs in metazoa, Curr. Biol. CB. 14 (2004) 1985-1995. doi:10.1016/j.cub.2004.11.003.

[172] N. Krogh, U. Birkedal, H. Nielsen, RiboMeth-seq: Profiling of 2'-O-Me in RNA, Methods Mol. Biol. Clifton NJ. 1562 (2017) 189-209. doi:10.1007/978-1-4939-6807-7_13.

[173] G. Kawai, H. Ue, M. Yasuda, K. Sakamoto, T. Hashizume, J.A. McCloskey, T. Miyazawa, S. Yokoyama, Relation between functions and conformational characteristics of modified nucleosides found in tRNAs, Nucleic Acids Symp. Ser. (1991) 49-50.

[174] B.G. Lane, T. Tamaoki, Studies of the chain termini and alkali-stable dinucleotide sequences in $16 \mathrm{~s}$ and $28 \mathrm{~s}$ ribosomal RNA from L cells, J. Mol. Biol. 27 (1967) 335-348.

[175] A.R. Trim, J.E. Parker, Preparation, purification and analyses of thirteen alkali-stable dinucleotides from yeast ribonucleic acid, Biochem. J. 116 (1970) 589-598.

[176] V.J. Bardwell, M. Wickens, S. Bienroth, W. Keller, B.S. Sproat, A.I. Lamond, Site-directed ribose methylation identifies 2'-OH groups in polyadenylation substrates critical for AAUAAA recognition and poly(A) addition, Cell. 65 (1991) 125-133.

[177] D.M. Mishler, A.B. Christ, J.A. Steitz, Flexibility in the site of exon junction complex deposition revealed by functional group and RNA secondary structure alterations in the splicing substrate, RNA N. Y. N. 14 (2008) 2657-2670. doi:10.1261/rna.1312808.

[178] C.B.F. Andersen, L. Ballut, J.S. Johansen, H. Chamieh, K.H. Nielsen, C.L.P. Oliveira, J.S. Pedersen, B. Séraphin, H. Le Hir, G.R. Andersen, Structure of the exon junction core complex with a trapped DEADbox ATPase bound to RNA, Science. 313 (2006) 1968-1972. doi:10.1126/science.1131981.

[179] H. Iribe, K. Miyamoto, T. Takahashi, Y. Kobayashi, J. Leo, M. Aida, K. Ui-Tei, Chemical Modification of the siRNA Seed Region Suppresses Off-Target Effects by Steric Hindrance to Base-Pairing with Targets, ACS Omega. 2 (2017) 2055-2064. doi:10.1021/acsomega.7b00291.

[180] J.A. Kowalak, J.J. Dalluge, J.A. McCloskey, K.O. Stetter, The role of posttranscriptional modification in stabilization of transfer RNA from hyperthermophiles, Biochemistry. 33 (1994) 7869-7876.

[181] P.F. Agris, H. Koh, D. Söll, The effect of growth temperatures on the in vivo ribose methylation of Bacillus stearothermophilus transfer RNA, Arch. Biochem. Biophys. 154 (1973) 277-282. 
[182] F. Kirpekar, L.H. Hansen, A. Rasmussen, J. Poehlsgaard, B. Vester, The archaeon Haloarcula marismortui has few modifications in the central parts of its $23 \mathrm{~S}$ ribosomal RNA, J. Mol. Biol. 348 (2005) 563-573. doi:10.1016/j.jmb.2005.03.009.

[183] K.R. Noon, E. Bruenger, J.A. McCloskey, Posttranscriptional modifications in 165 and $23 S$ rRNAs of the archaeal hyperthermophile Sulfolobus solfataricus, J. Bacteriol. 180 (1998) 2883-2888.

[184] M. Abe, A. Naqvi, G.-J. Hendriks, V. Feltzin, Y. Zhu, A. Grigoriev, N.M. Bonini, Impact of age-associated increase in 2'-O-methylation of miRNAs on aging and neurodegeneration in Drosophila, Genes Dev. 28 (2014) 44-57. doi:10.1101/gad.226654.113.

[185] D. Vázquez, Inhibitors of protein biosynthesis, Mol. Biol. Biochem. Biophys. 30 (1979) i-x, 1-312.

[186] A. La Teana, C.O. Gualerzi, A.E. Dahlberg, Initiation factor IF 2 binds to the alpha-sarcin loop and helix 89 of Escherichia coli 23 S ribosomal RNA, RNA N. Y. N. 7 (2001) 1173-1179.

[187] S. Douthwaite, Interaction of the antibiotics clindamycin and lincomycin with Escherichia coli $23 \mathrm{~S}$ ribosomal RNA, Nucleic Acids Res. 20 (1992) 4717-4720.

[188] S.M. Poulsen, M. Karlsson, L.B. Johansson, B. Vester, The pleuromutilin drugs tiamulin and valnemulin bind to the RNA at the peptidyl transferase centre on the ribosome, Mol. Microbiol. 41 (2001) 1091-1099.

[189] A. Bechthold, H.G. Floss, Overexpression of the thiostrepton-resistance gene from Streptomyces azureus in Escherichia coli and characterization of recognition sites of the 23 S rRNA A1067 2'methyltransferase in the guanosine triphosphatase center of $23 \mathrm{~S}$ ribosomal RNA, Eur. J. Biochem. 224 (1994) 431-437.

[190] I. Treede, L. Jakobsen, F. Kirpekar, B. Vester, G. Weitnauer, A. Bechthold, S. Douthwaite, The avilamycin resistance determinants AviRa and AviRb methylate $23 \mathrm{~S} \mathrm{rRNA}$ at the guanosine 2535 base and the uridine 2479 ribose, Mol. Microbiol. 49 (2003) 309-318.

[191] H.J. Sofia, G. Chen, B.G. Hetzler, J.F. Reyes-Spindola, N.E. Miller, Radical SAM, a novel protein superfamily linking unresolved steps in familiar biosynthetic pathways with radical mechanisms: functional characterization using new analysis and information visualization methods, Nucleic Acids Res. 29 (2001) 1097-1106.

[192] C. Kehrenberg, S. Schwarz, L. Jacobsen, L.H. Hansen, B. Vester, A new mechanism for chloramphenicol, florfenicol and clindamycin resistance: methylation of $23 \mathrm{~S}$ ribosomal RNA at A2503, Mol. Microbiol. 57 (2005) 1064-1073. doi:10.1111/j.1365-2958.2005.04754.x.

[193] J. Esguerra, J. Warringer, A. Blomberg, Functional importance of individual rRNA 2'-O-ribose methylations revealed by high-resolution phenotyping, RNA N. Y. N. 14 (2008) 649-656. doi:10.1261/rna.845808.

[194] G. Dönmez, K. Hartmuth, R. Lührmann, Modified nucleotides at the 5' end of human U2 snRNA are required for spliceosomal E-complex formation, RNA N. Y. N. 10 (2004) 1925-1933. doi:10.1261/rna.7186504.

[195] J. Ge, H. Liu, Y.-T. Yu, Regulation of pre-mRNA splicing in Xenopus oocytes by targeted 2'-Omethylation, RNA N. Y. N. 16 (2010) 1078-1085. doi:10.1261/rna.2060210.

[196] H. Dong, K. Fink, R. Züst, S.P. Lim, C.-F. Qin, P.-Y. Shi, Flavivirus RNA methylation, J. Gen. Virol. 95 (2014) 763-778. doi:10.1099/vir.0.062208-0.

[197] S.S. Bradrick, Causes and Consequences of Flavivirus RNA Methylation, Front. Microbiol. 8 (2017) 2374. doi:10.3389/fmicb.2017.02374.

[198] D.C. Chang, L.T. Hoang, A.N. Mohamed Naim, H. Dong, M.J. Schreiber, M.L. Hibberd, M.J.A. Tan, P.-Y. Shi, Evasion of early innate immune response by 2'-O-methylation of dengue genomic RNA, Virology. 499 (2016) 259-266. doi:10.1016/j.virol.2016.09.022.

[199] Y.M. Abbas, B.T. Laudenbach, S. Martínez-Montero, R. Cencic, M. Habjan, A. Pichlmair, M.J. Damha, J. Pelletier, B. Nagar, Structure of human IFIT1 with capped RNA reveals adaptable mRNA binding and mechanisms for sensing N1 and N2 ribose 2'-O methylations, Proc. Natl. Acad. Sci. U. S. A. 114 (2017) E2106-E2115. doi:10.1073/pnas.1612444114.

[200] R. Züst, L. Cervantes-Barragan, M. Habjan, R. Maier, B.W. Neuman, J. Ziebuhr, K.J. Szretter, S.C. Baker, W. Barchet, M.S. Diamond, S.G. Siddell, B. Ludewig, V. Thiel, Ribose 2'-O-methylation provides a molecular signature for the distinction of self and non-self mRNA dependent on the RNA sensor 
Mda5, Nat. Immunol. 12 (2011) 137-143. doi:10.1038/ni.1979.

[201] T.P. Hoernes, N. Clementi, K. Faserl, H. Glasner, K. Breuker, H. Lindner, A. Hüttenhofer, M.D. Erlacher, Nucleotide modifications within bacterial messenger RNAs regulate their translation and are able to rewire the genetic code, Nucleic Acids Res. 44 (2016) 852-862. doi:10.1093/nar/gkv1182.

[202] J. Choi, G. Indrisiunaite, H. DeMirci, K.-W. leong, J. Wang, A. Petrov, A. Prabhakar, G. Rechavi, D. Dominissini, C. He, M. Ehrenberg, J.D. Puglisi, 2'-O-methylation in mRNA disrupts tRNA decoding during translation elongation, Nat. Struct. Mol. Biol. 25 (2018) 208-216. doi:10.1038/s41594-0180030-z.

[203] S. Jung, T. von Thülen, V. Laukemper, S. Pigisch, D. Hangel, H. Wagner, A. Kaufmann, S. Bauer, A single naturally occurring 2'-O-methylation converts a TLR7- and TLR8-activating RNA into a TLR8-specific ligand, PloS One. 10 (2015) e0120498. doi:10.1371/journal.pone.0120498.

[204] A.D. Judge, G. Bola, A.C.H. Lee, I. MacLachlan, Design of noninflammatory synthetic siRNA mediating potent gene silencing in vivo, Mol. Ther. J. Am. Soc. Gene Ther. 13 (2006) 494-505. doi:10.1016/j.ymthe.2005.11.002.

[205] S. Gehrig, M.-E. Eberle, F. Botschen, K. Rimbach, F. Eberle, T. Eigenbrod, S. Kaiser, W.M. Holmes, V.A. Erdmann, M. Sprinzl, G. Bec, G. Keith, A.H. Dalpke, M. Helm, Identification of modifications in microbial, native tRNA that suppress immunostimulatory activity, J. Exp. Med. 209 (2012) 225-233. doi:10.1084/jem.20111044.

[206] K. Rimbach, S. Kaiser, M. Helm, A.H. Dalpke, T. Eigenbrod, 2'-O-Methylation within Bacterial RNA Acts as Suppressor of TLR7/TLR8 Activation in Human Innate Immune Cells, J. Innate Immun. 7 (2015) 482-493. doi:10.1159/000375460.

[207] M. Robbins, A. Judge, L. Liang, K. McClintock, E. Yaworski, I. MacLachlan, 2'-O-methyl-modified RNAs act as TLR7 antagonists, Mol. Ther. J. Am. Soc. Gene Ther. 15 (2007) 1663-1669. doi:10.1038/sj.mt.6300240.

[208] S. Kaiser, K. Rimbach, T. Eigenbrod, A.H. Dalpke, M. Helm, A modified dinucleotide motif specifies tRNA recognition by TLR7, RNA N. Y. N. 20 (2014) 1351-1355. doi:10.1261/rna.044024.113.

[209] S. Higa-Nakamine, T. Suzuki, T. Uechi, A. Chakraborty, Y. Nakajima, M. Nakamura, N. Hirano, T. Suzuki, N. Kenmochi, Loss of ribosomal RNA modification causes developmental defects in zebrafish, Nucleic Acids Res. 40 (2012) 391-398. doi:10.1093/nar/gkr700.

[210] F. Zhou, Y. Liu, C. Rohde, C. Pauli, D. Gerloff, M. Köhn, D. Misiak, N. Bäumer, C. Cui, S. Göllner, T. Oellerich, H. Serve, M.-P. Garcia-Cuellar, R. Slany, J.P. Maciejewski, B. Przychodzen, B. Seliger, H.-U. Klein, C. Bartenhagen, W.E. Berdel, M. Dugas, M.M. Taketo, D. Farouq, S. Schwartz, A. Regev, J. Hébert, G. Sauvageau, C. Pabst, S. Hüttelmaier, C. Müller-Tidow, AML1-ETO requires enhanced C/D box snoRNA/RNP formation to induce self-renewal and leukaemia, Nat. Cell Biol. 19 (2017) 844-855. doi:10.1038/ncb3563. 


\section{Figure legends}

Figure 1 a) Chemical structures of common RNA 2'-O-methylated nucleotides (Am, Gm, Um, Cm, Im and $\psi \mathrm{m})$, b) hallmarks of studies on RNA 2'-O-methylation from 1960 to 2000.

Figure 2 Top. 2'-O-methylated positions in tRNAs from Eubacteria (E. coli), Archaea (H. volcanii) and Eukarya (S. cerevisiae and vertebrates). S. cerevisiae sites are shown in light blue, additional human sites in dark blue. Bottom part represents tRNA cloverleaf structure with the indicated modified positions.

Figure 3 a) Human $18 \mathrm{~S}$ rRNA 2'-O-methylation. The 2D structure of human $18 \mathrm{~S}$ rRNA is represented by wire. $2^{\prime}$-O-methylated residues and their numbering are shown. Previously annotated human 2'-O-methylated sites (https://people.biochem.umass.edu/fournierlab/3dmodmap/main.php) are in green, newly identified positions are in yellow. 2'-O-methylated pseudouridine at position 1326 is in brown color. Conservation with S.cerevisiae (in blue) and E.coli (in red) 2'-O-methylation is shown.

b) Human $28 \mathrm{~S}$ and $5.8 \mathrm{~S}$ rRNA 2'-O-methylations. The 2D structure of human $28 \mathrm{~S}$ rRNA is represented by wire, 5.8S rRNA is in red. Previously annotated human 2'-0-methylated sites (https://people.biochem.umass.edu/fournierlab/3dmodmap/main.php) are in green, newly identified positions are in yellow. Numbering corresponds to "new" reference NR_046235. 2 '-O-methylated pseudouridine at position 3818 is in brown color. Conservation with S.cerevisiae (in blue) and E.coli (in red) 2'-O-methylation sites is shown.

Figure $4 \quad$ Reported human snRNA 2'-O-methylations. $\mathrm{m}^{2,2,7} \mathrm{G}$-Cap is shown as a star. $\gamma$-methyl cap of U6 snRNA is represented by a blue star. 2'-O-methylation sites are indicated by green circles.

Figure 5 General view of 2'-O-methylation machinery in human cells. 2'-O-methylation sites are in green circles. Enzymes (if known) are shown.

Figure $6 \quad$ Structure of C/D-box sno(s)RNPs in different species. 

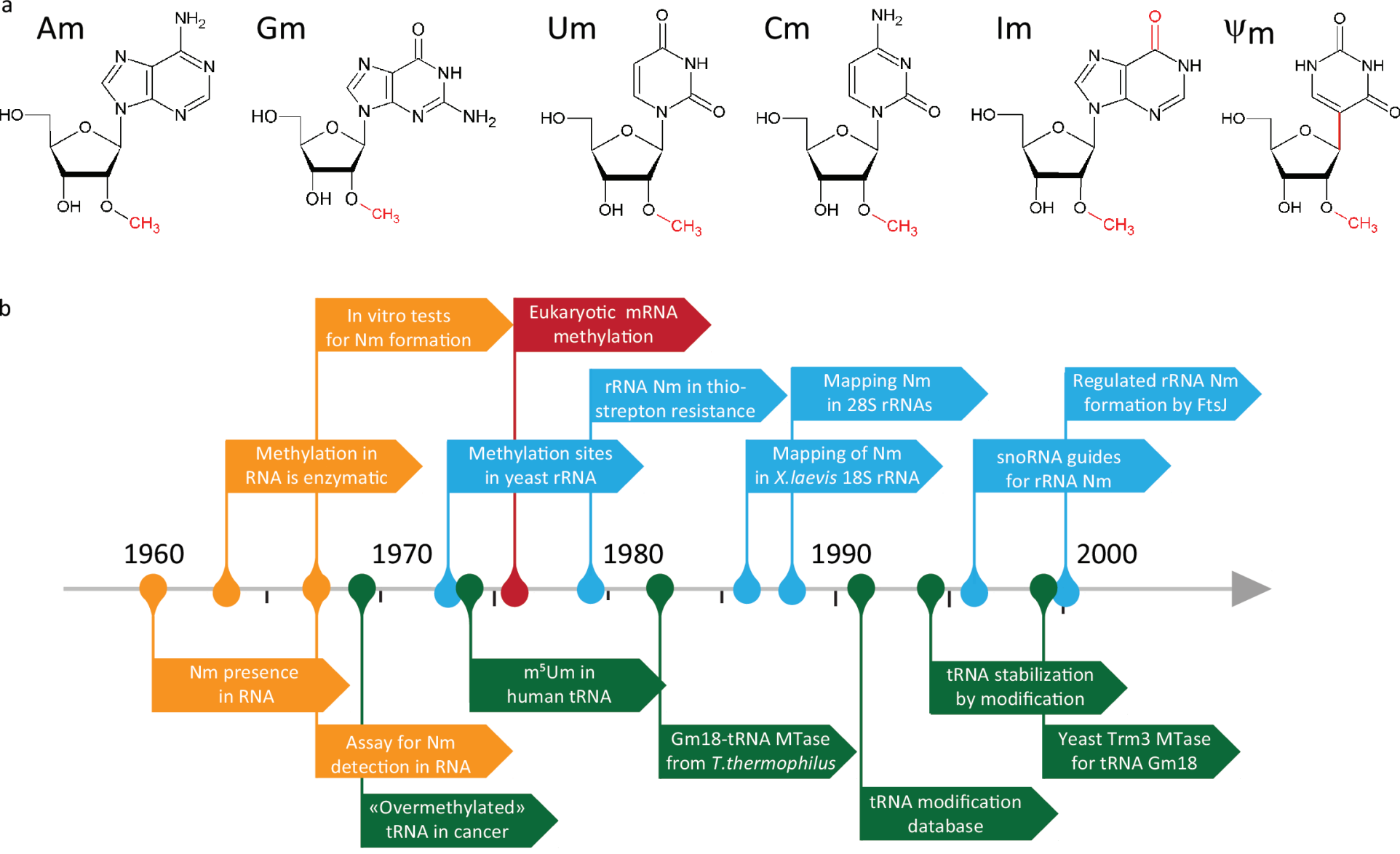

Figure 1 Ayadi et al 
Eubacteria

(E.coli)

Archaeabacteria

Eukarya 


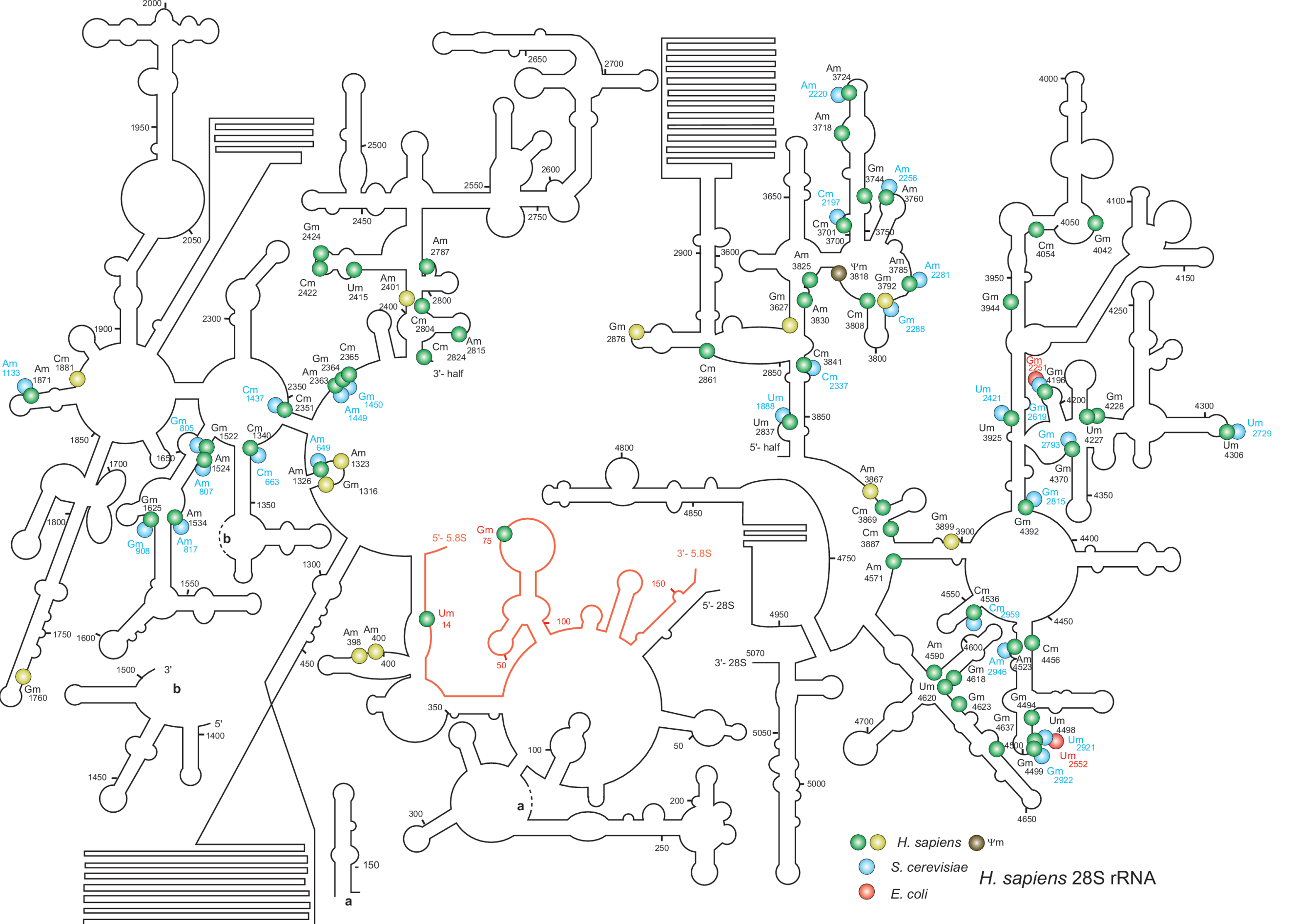

Figure $3 b$ Ayadi et a 


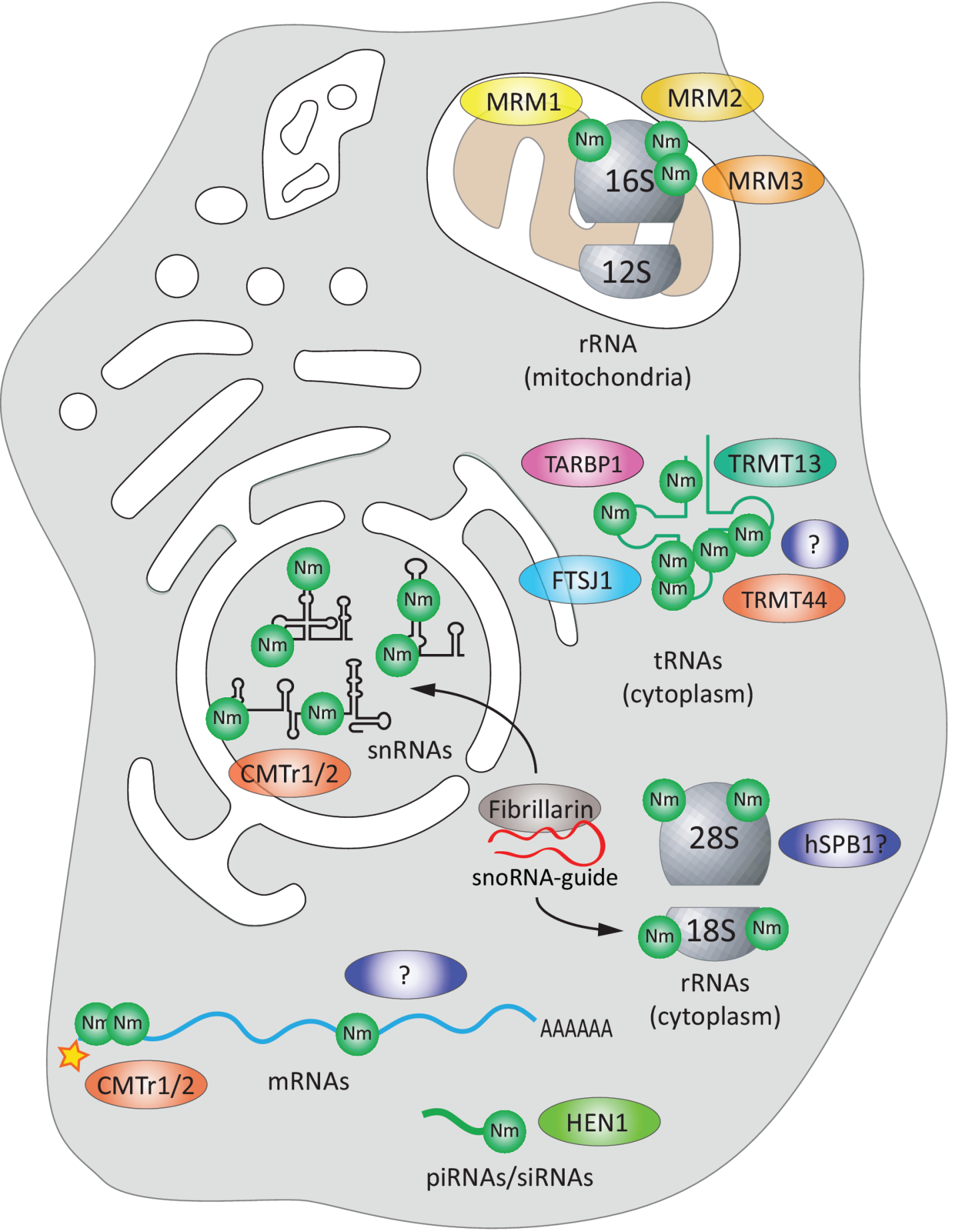

Figure 5 Ayadi et al 
